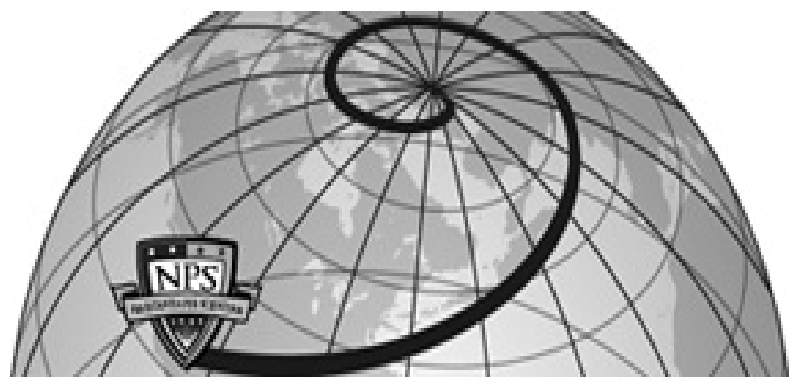

Calhoun: The NPS Institutional Archive DSpace Repository

\title{
A laboratory experiment on surface wave attenuation due to underwater turbulence.
}

Paquin, James Edward

Monterey, California. Naval Postgraduate School

https://hdl.handle.net/10945/12530

Downloaded from NPS Archive: Calhoun

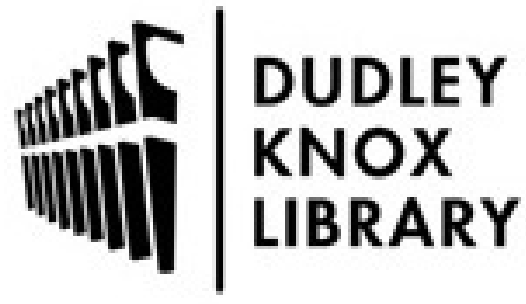

http://www.nps.edu/library
Calhoun is the Naval Postgraduate School's public access digital repository for research materials and institutional publications created by the NPS community. Calhoun is named for Professor of Mathematics Guy K. Calhoun, NPS's first appointed -- and published -- scholarly author.

Dudley Knox Library / Naval Postgraduate School 411 Dyer Road / 1 University Circle Monterey, California USA 93943 
NPS ARCHIVE

1968

PAQUIN, J.

A LABORATORY EXPERIMENT ON

SURFACE WAVE ATTENUATION DUE TO

UNDERWATER TURBULENCE

by

James Edward Paquin 



\section{UNITED STATES \\ NAVAL POSTGRADUATE SCHOOL}

\section{THESIS}

A LABORATORY EXPERIMENT ON

SURFACE WAVE ATTENUATION DUE TO

UNDERWATER TURBULENCE

James Edward Paquin

December 1968

This document has been approved for public release and sale; its distribution is unlimited. 


\section{LIBRARY}

NAVAL POSTGRADUATE SCHOOL

MONTEREY, CALIF. 93940 
A LABORATORY EXPERIMENT ON

SURFACE WAVE ATTENUATION DUE TO

UNDERWATER TURBULENCE

by

James Edward Paquin

Lieutenant, United States Navy

B.S., United States Naval Academy, 1962

Submitted in partial fulfillment of the requirements for the degree of

MASTER OF SCIENCE IN OCEANOGRAPHY

from the

NAVAL POSTGRADUATE SCHOOL

December 1968 


\section{TABLE OF CONTENTS}

Section

Page

1. INTRODUCTION

Objective

Outline of Experiment

2. EQUIPMENT

Wave Tank

Wave Generator

Turbulence Generator

Wave Probe Design and Calibration

Anemometer Function and Calibration

3. SPECTRA OF THE PADDLE-DRIVEN WAVES

4. TURBULENCE SPECTRA

5. ATTENUATION OF WAVES DUE TO TURBULENCE

6. PHASE SHIFT IN THE TURBULENT ZONE

7. ATTENUATION OF WIND-DRIVEN WAVES

8. SUMMARY AND CONCLUSIONS 



\section{LIST OF TABLES}

Table

Page

1 Typical Values of Energy Losses 

Figure

Page

1. Schematic Diagram of Wave Tank

2. Turbulence Generator

3. Wave Probe Circuit

4. Typical Wave Probe Calibration Curve

5. Dynamic Calibration of Wave Probes

6. Typical Anemometer Calibration Curve

7. RMS Height Distribution for Paddle-Driven Waves at Probe \#1 and \#2

8. Spectral Analysis for a 1.2 Hertz Wave

9. Spectral Analysis for a 1.8 Hertz Wave

10. Spectral Analysis for a 2.4 Hertz Wave

11. Spectral Analysis for a 3.1 Hertz Wave

12. Spectral Analysis for a 3.5 Hertz Wave

13. Spectral Analysis for a 4.0 Hertz Wave

14. Spectral Analysis for a 4.1 Hertz Wave

15. Wave Attenuation due to Distance

16. Velocity Distributions in the Turbulent Region for a 3.1 Hertz Wave

17. Effect of Turbulence on 1.2 Hertz Wave

18. Effect of Turbulence on 1.8 Hertz Wave

19. Effect of Turbulence on 2.4 Hertz Wave

20. Effect of Turbulence on 3.1 Hertz Wave

21. Effect of Turbulence on 3.5 Hertz Wave

22. Effect of Turbulence on 4.0 Hertz Wave 
23. Effect of Turbulence on 4.1 Hertz Wave 48

24. Percent Wave Attenuation due to Turbulence 49

25. Attenuation of Waves due to Turbulence Plotted as a Function of Number of Wavelengths in the Turbulent Region

26. Phase Shift Versus Frequency 55

27. Attenuation of the Model sea Surface 58 


\section{ACKNOWLEDGMENTS}

The author wishes to express his sincere appreciation to Drs. H. Medwin and T. Green III for their guidance and assistance in completing this project. 

A LABORATORY EXPERIMENT ON

SURFACE WAVE ATTENUATION DUE TO

UNDERWATER TURBULENCE

\section{Introduction}

\section{Objective}

The objective of this experiment was to determine, quantitatively, the effect that a zone of underwater turbulence has on a gravity wave which passes through it.

P. Groen [1954, p.7] predicted that a decay in amplitude and an apparent increase in period of swell would occur after a gravity wave train passed through a turbulent region, and that this effect is related to external turbulence, that is, turbulence which is produced independently of the wave. Groen further predicted that this effect depends on both wavelength of the waves and characteristic wavelength of the turbulence.

Groen also states that gravity waves may be affected by self-produced or internal turbulence. This will not be considered in this paper.

T. P. Barnett [1968] states that one of the possible drawbacks of the present scheme of predicting generating and dissipation of ocean waves is the neglect of some unknown dissipative mechanism. Since his scheme did not account for external turbulence, the interactions between waves and turbulence may provide the needed explanation for loss of wave energy. 
Because of the difficulties of precise measurement of waves and turbulence at sea, this possible energy dissipation was studied in a laboratory experiment.

\section{Outline of Experiment}

A wave tank equipped with wave and turbulence generating devices was used to produce the desired experimental conditions. A traveling surface wave was generated at one end of the tank and absorbed by a porous beach at the opposite end. The wave passed through a zone of turbulence, produced by an oscillating grid in the center of the tank bottom. The effect of the turbulent region on the wave was evaluated by wave height measurements taken with two resistance-type probes located on each side of the turbulent region. Measurements of turbulent velocities were taken with a constant temperature anemometer. 


\section{Equipment}

\section{Wave Tank}

Dimensions of the rectangular-shaped wave tank used in this experiment are shown in Figure 1.

A false bottom installed in the tank isolated the driving mechanism for the oscillating grid and prevented it from generating currents which might advect turbulence beyond the desired region. The false bottom was stepped down in the center of the tank (Figure 1) to accomodate the grid which was supported by four metal rods. Since the turbulence generator was located entirely below the false bottom, no equipment penetrated the water's surface except the chain drive for the turbulence generator. A false side of the tank prevented this chain from interfering with the wave as it traveled down the tank.

The effective depth for the higher-frequency waves generated was the depth of the false bottom, approximately 12 centimeters. When lower frequency waves were generated, the false bottom was removed, allowing currents to form. The effect of these currents on the experiment appeared to be negligible.

Only deep-water waves were studied to avoid complications resulting from the effects of reflection of shallowwater waves which would occur in the stepped-down region. (Deep-water, in this experiment, refers to waves whose ratio of depth to wavelength is greater than or equal to one-half.) 


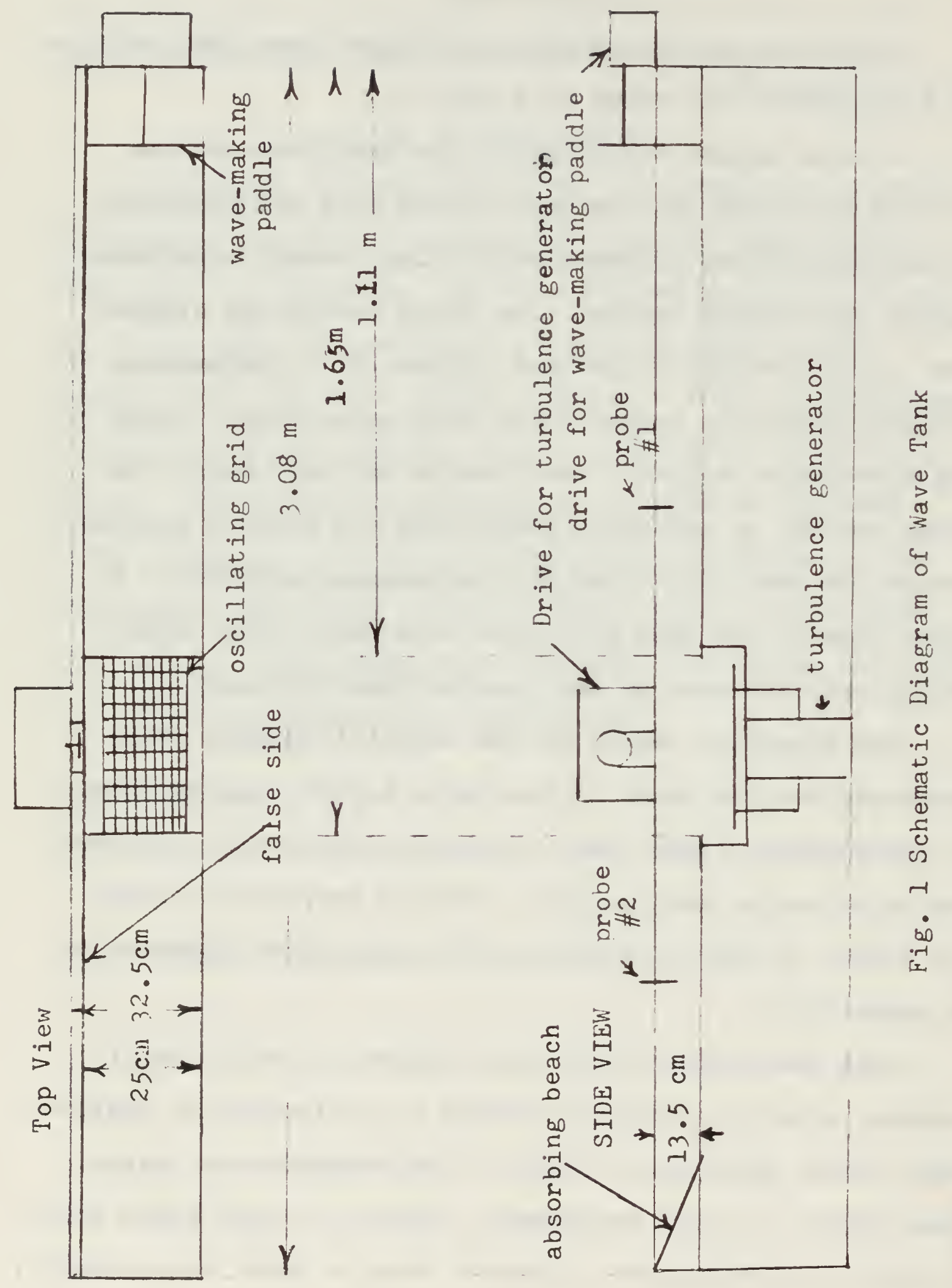




\section{Wave Generator}

Waves were generated at one end of the tank by a flat aluminum paddle driven by a variable-speed motor. The period of the wave generated depended on the speed of the motor; the wave height depended on the stroke length of the paddle. The equipment used provided two paddle-stroke lengths and continuous changes of motor speed.

\section{Turbulence Generator}

Turbulence was generated by a vertically-oscillating grid located in the center of the wave tank just above the false bottom. Various screening materials were tried for the grid, but it was found that only screening with a large, solid surface-to-hole ratio would generate turbulence strong enough to disturb the near-surface area of the water. The grid screen used for this experiment was woven of metal strips one centimeter wide, set one centimeter apart across the width of the grid and two centimeters apart lengthwise.

The grid was oscillated by apparatus located beneath the false bottom of the tank (Figure 2). All moving parts of this apparatus were lubricated by the water which surrounded them. A frame, connected to the grid by four bolts which penetrated the bottom of the tank, was moved up and down by a piston driven through a crankshaft. A chain drive connected the crankshaft (through the false side) to an electric motor located just above the tank. 
support and bearing assembly for driveshaft
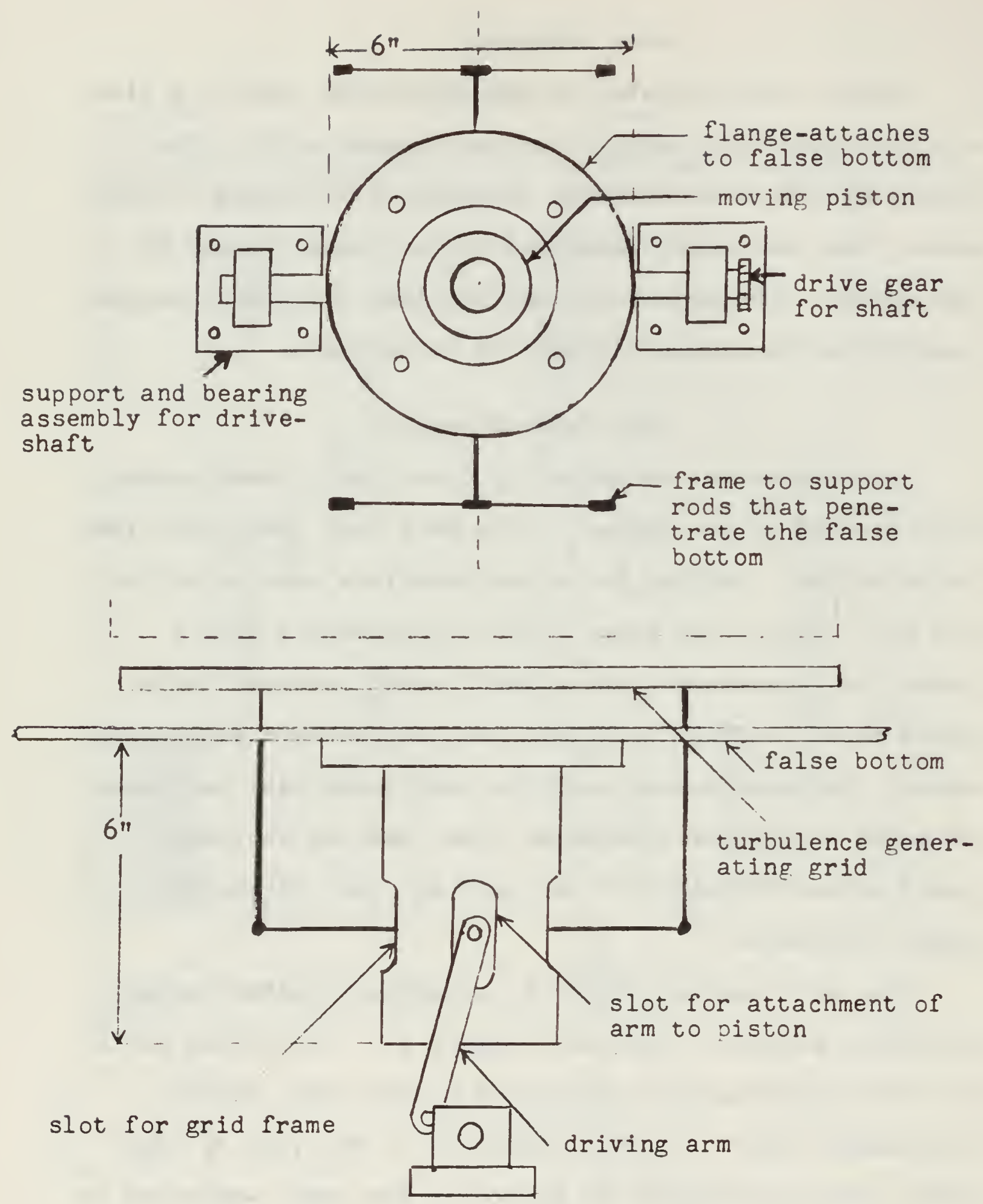

(not to scale)

Fig. 2 Turbulence Generator 
Wave Probe Design and Calibration

Resistance-type wave probes were used to measure wave height outside the turbulent zone. The probes operate on the principle that two parallel wires immersed in water, so that the plane of wires is parallel to wave crests, will have a resistance that is a function of the depth of immersion. A block diagram of the probe circuit is shown in Figure 3. The power supply is an audio oscillator. The probe, which consists of two wires supported by an insulating block, is in parallel with one leg of a balanced bridge circuit. As the water level varies on the wires, the AC signal from the audio oscillator is amplitude modulated. The bridge output is amplified, and then converted by a demodulator from an amplitude-modulated AC signal to a varying DC signal. This signal can then be recorded on magnetic tape, strip chart or other suitable recorder.

Static calibration of the wave probes was accomplished by changing the depth of immersion of the probes and plotting the water level versus the DC output of the probe circuit. Figure 4 shows a typical plot of output versus water level. The magnitude of the linear range for the probes used was in excess of 7 centimeters. Since the wave heights generated were all less than this value, the static response of the probes imposed no significant restrictions on the experiment. Dynamic calibration of the wave probes was more difficult to accomplish than static calibration. The probe and a rod, graduated in millimeters, were placed in the wave tank 
Audio Osc.

Hewlett Packard

Model $200 \mathrm{AB}$
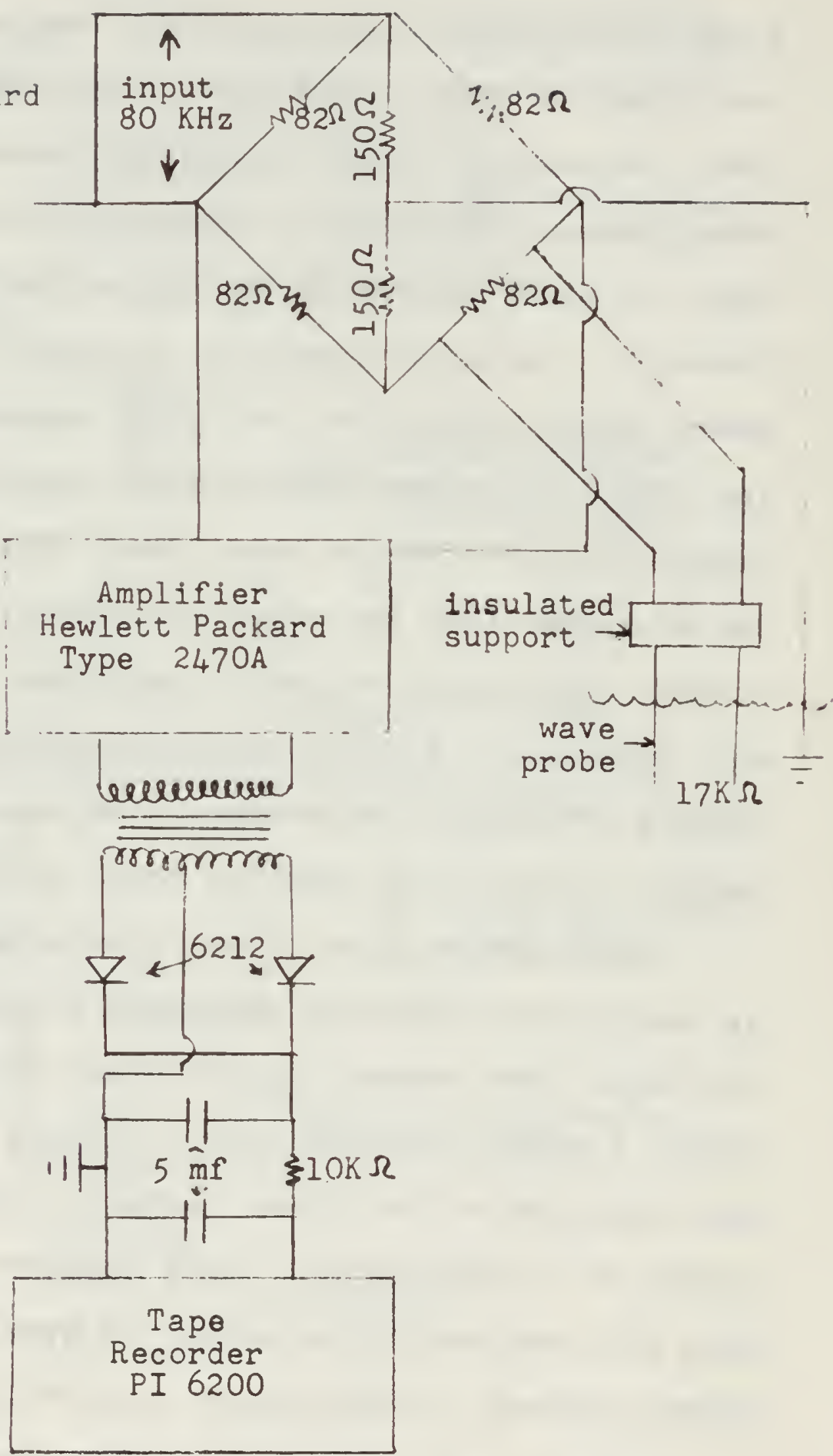

Fig. 3 Wave Probe Circuit 


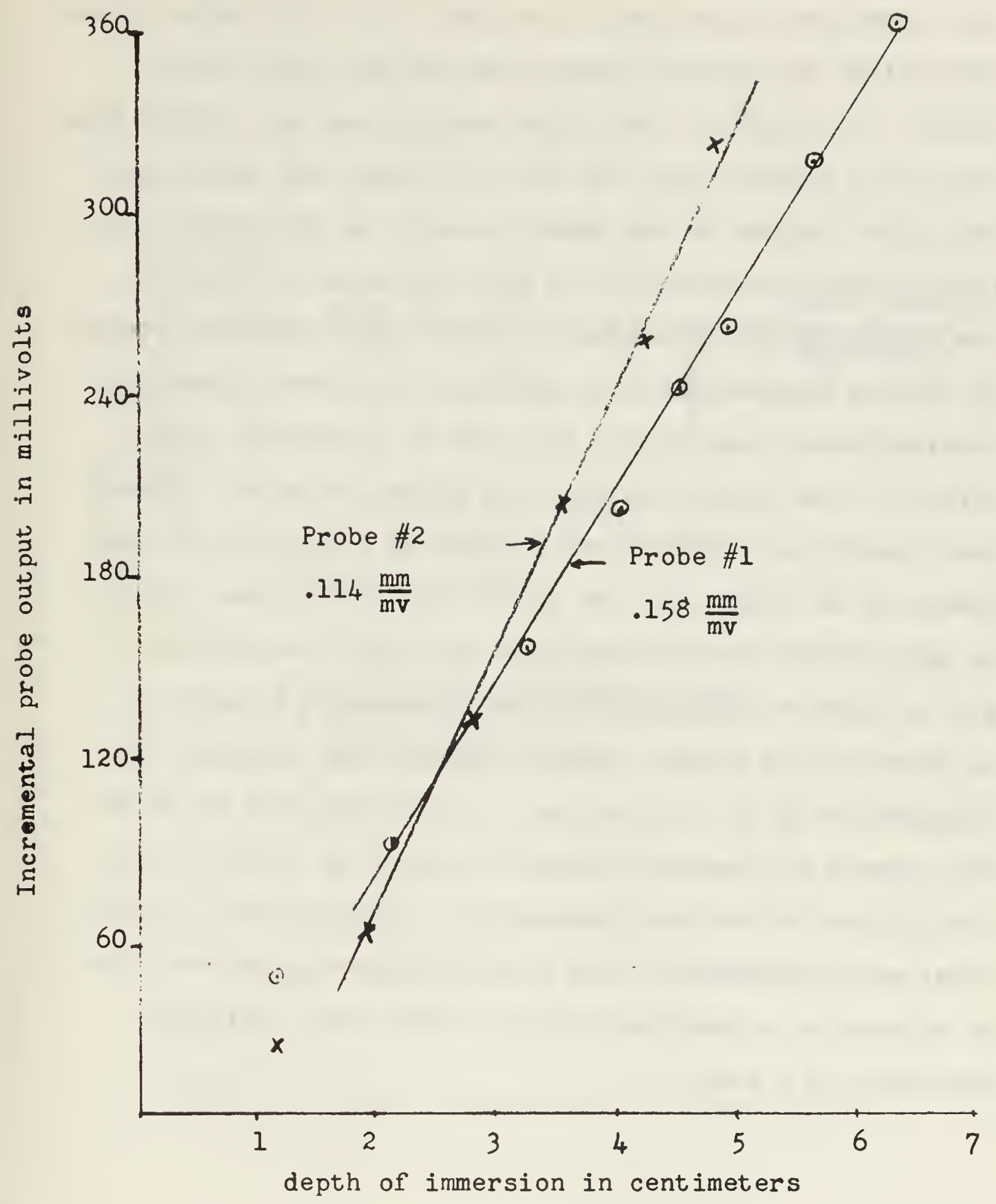

Fig. 4-Typical Wave Probe Calibration Curve 
in such a position that water level could be read on the rod. When waves were generated in the tank, the difference between the maximum and minimum reading on the rod gave the wave height. In order to facilitate reading the wave height from the rod, a strobe light was used to "stop" the wave train. The light flashed at the same frequency as the wave, illuminating only one phase of the wave and thus, eliminating the effect of the moving wave on the visual reading. Waves of various frequencies were generated and wave height was recorded both visually and from the DC calibrated probe circuit. The ratio of probe wave height to actual (visual) wave height was computed and plotted as a function of frequency as in Figure 5. The ideal ratio of voltage output to wave height was obtained from the static calibration and is shown as the value at zero frequency in Figure 5. As shown in the figure, height response was excellent for frequencies up to $4 \mathrm{~Hz}$ and was still fairly good at $26 \mathrm{~Hz}$. The absence of readings between 4 and $26 \mathrm{~Hz}$ is due to the limitations of the wave generators. (Frequencies $4 \mathrm{~Hz}$ and lower were generated by the afore-mentioned generator; the $26 \mathrm{~Hz}$ wave is a capillary wave of much lower amplitude generated by a fan.) 

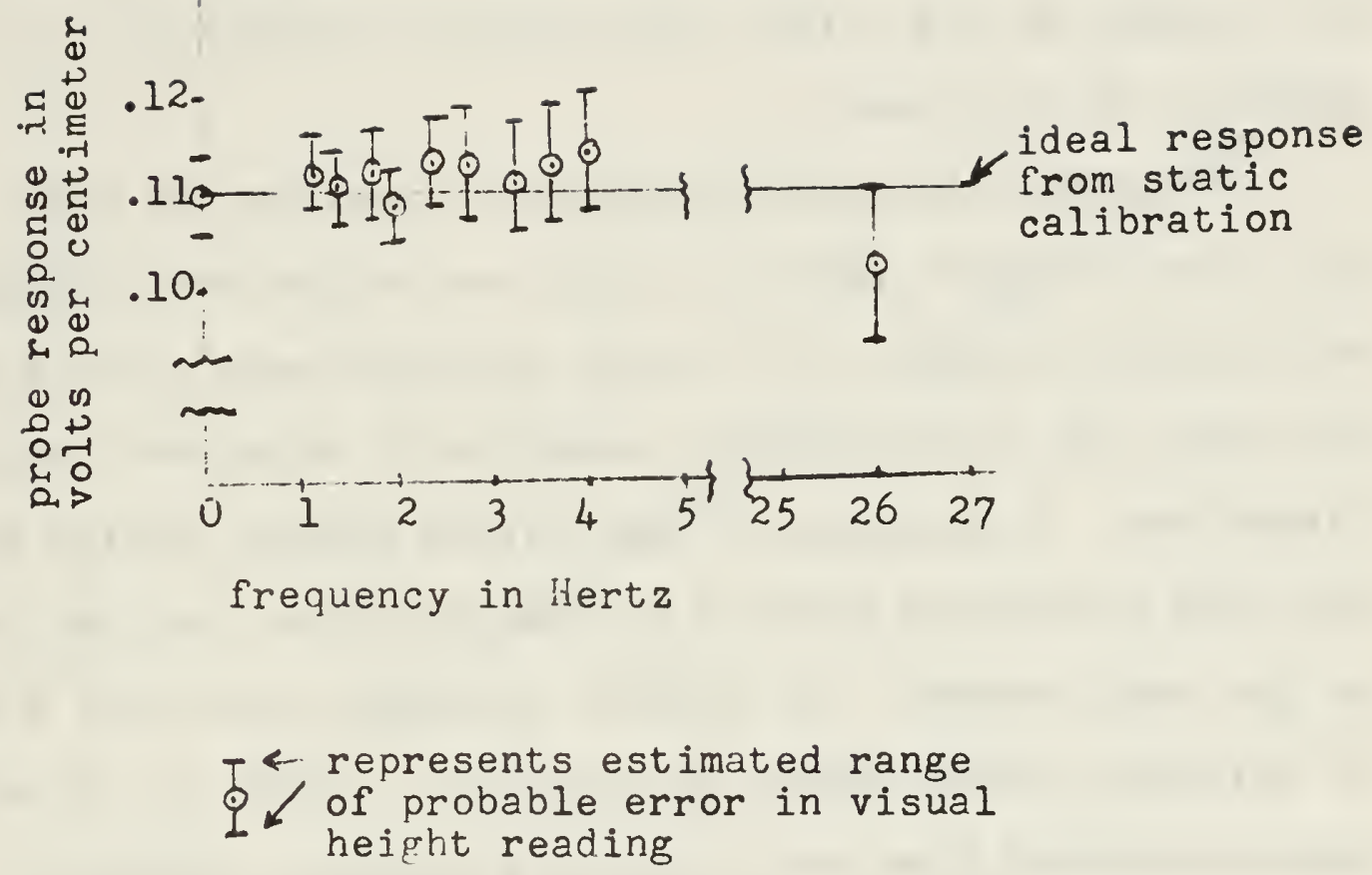

Fig. 5. Dynamic Calibration of Wave Probe 
A calibrated, quartz-coated, hot film probe was used with a DISA Constant Temperature Anemometer to measure particle velocities in the turbulent water region. A DISA Linearizer altered the output of the anemometer so that output voltage of the circuit was directly proportional to velocity of the fluid.

The anemometer was calibrated by putting the probe in a flow of known velocity which was varied and compared with output voltage. The values obtained were plotted and the curve was corrected for linearity by adjustment of the linearizer. A cylindrical tank fitted with an outlet pipe near the bottom was used to provide the flow. As the level in the tank changes, the outflow velocity varies and a plot of velocity versus output is obtained. Values of velocity were calculated from the simplified Bernoulli equation:

$$
U=(2 g h)^{\frac{1}{2}}
$$

$U$ is outflow velocity

$\mathrm{g}$ is acceleration due to gravity

$h$ is height of water in the tank

A typical calibration curve is shown in Figure 6 . The use of a constant temperature anemometer in this experiment had certain drawbacks:

The anemometer is normally used to measure small velocity fluctuations in a mean flow; the output of the 


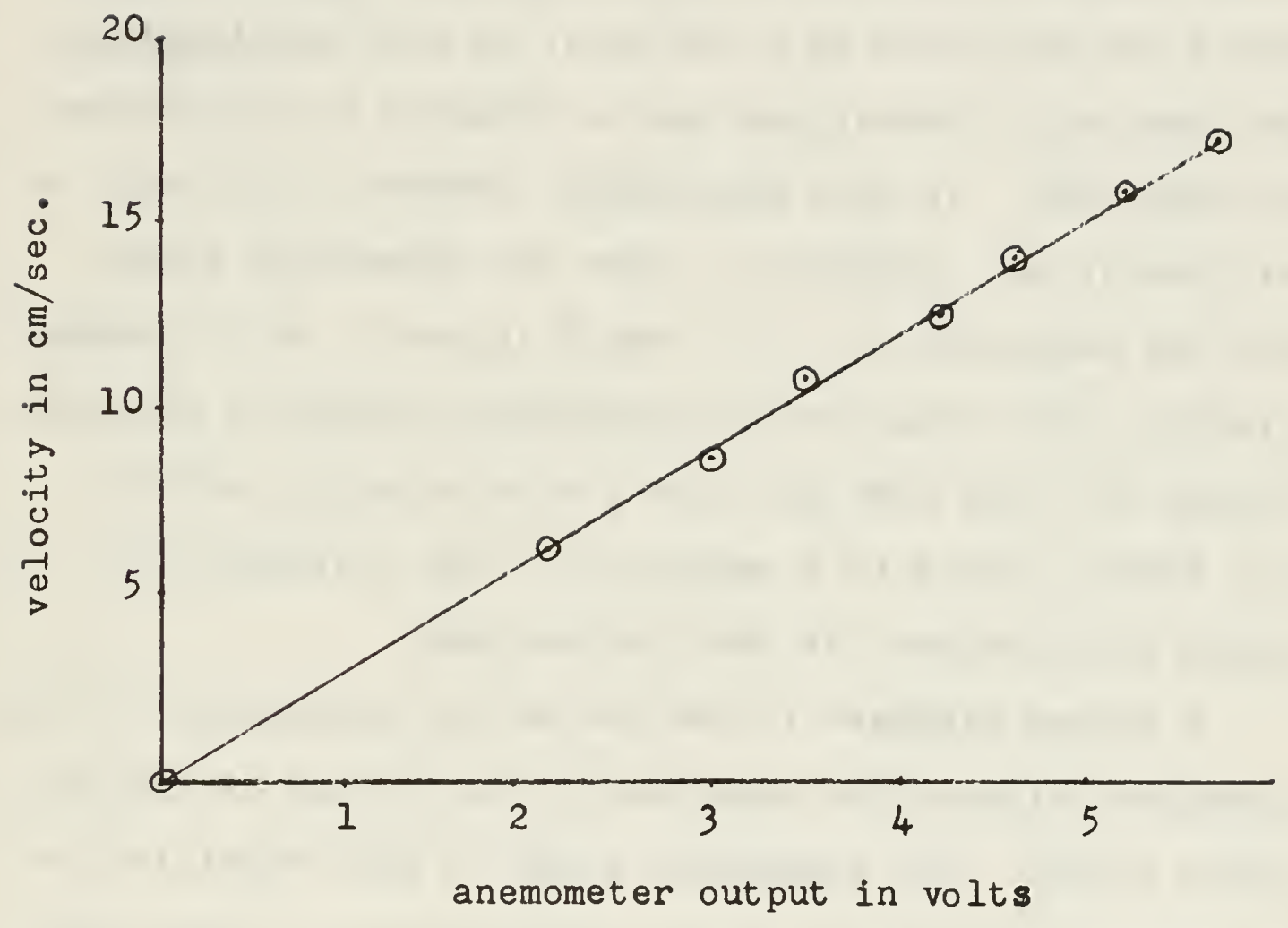

Fig.6-Typical Anemometer Calibration Curve 
anemometer is the sum of the mean flow and fluctuation:

$$
\mathrm{U}=\overline{\mathrm{U}}+\mathrm{U} *
$$

where $\bar{U}$ is mean flow velocity, $U^{*}$ is the time varying fluctuation and $U$ is the flow at any instant. The anemometer senses the magnitude of $U$ and thus, in most applications, the turbulent fluctuations can be obtained by subtracting the mean flow. In this experiment, however, $\bar{U}$ is zero, or very nearly so. Therefore, since the anemometer senses only the magnitude of $U$ ( $U^{*}$ when $\bar{U}$ is zero), as $U^{*}$ changes direction, the output of the anemometer remains a positive voltage and thus does not give a true velocity profile. As a result, there is a tendency for the instrument to double the frequency of the fluctuations.

A second drawback in the use of the anemometer in this experiment affects the magnitude of velocities in the turbulent region. The anemometer probe is most sensitive to the component of flow velocity perpendicular to the film. When flow in the tank reverses, it passes back over the posterior of the probe. The probe, therefore, influences the flow physically. When measureing this altered flow, the probe is also measuring a flow velocity moving in a direction opposite from the flow direction it has been calibrated to measure.

When probe orientation was reversed in a constant flow of known unidirectional velocity, probe response was measured 
at 20 to $25 \%$ of the true value for velocities of five to six $\mathrm{cm} / \mathrm{sec}$. Because of this reduced sensitivity, the probe tended to respond primarily to velocities in one direction; however, the response in the opposite direction is great enough to make interpretation of the probe output very un:ertain. 
3. Spectra of the Paddle-Driven Surface Waves

The spectral energy of the waves produced by the wave generator was strongest at the frequency of oscillation of the paddle. However, Figure 7, which is a plot of rootmean-square height distribution versus frequency, shows that there was also energy at the second and third harmonics of the paddle frequency.

The distribution of wave height with frequency was determined as follows:

1. The wave generator was run until a steady state was approximated (i.e., until the waves in the tank no longer increased in height).

2. Wave height was measured at the two probe positions when no turbulence was being generated.

3. The outputs of the two probes were recorded on a PI 6200 magnetic tape recorder operating at .375 inches per second.

4. The tape was then played back at 3.75 inches per second and the output was analyzed with a General Radio Company Type 1900 Wave Analyzer. (The tape was played back at ten times recorded speed so that waves of $\mathrm{l} \mathrm{Hz}$ and greater could be measured since the effective low frequency limit of the analyzer is $10 \mathrm{~Hz}$.)

In an application where the signal measured is broad band (i.e., for study of the turbulence spectrum) the meter of the wave analyzer indicates the value of the instantaneous 


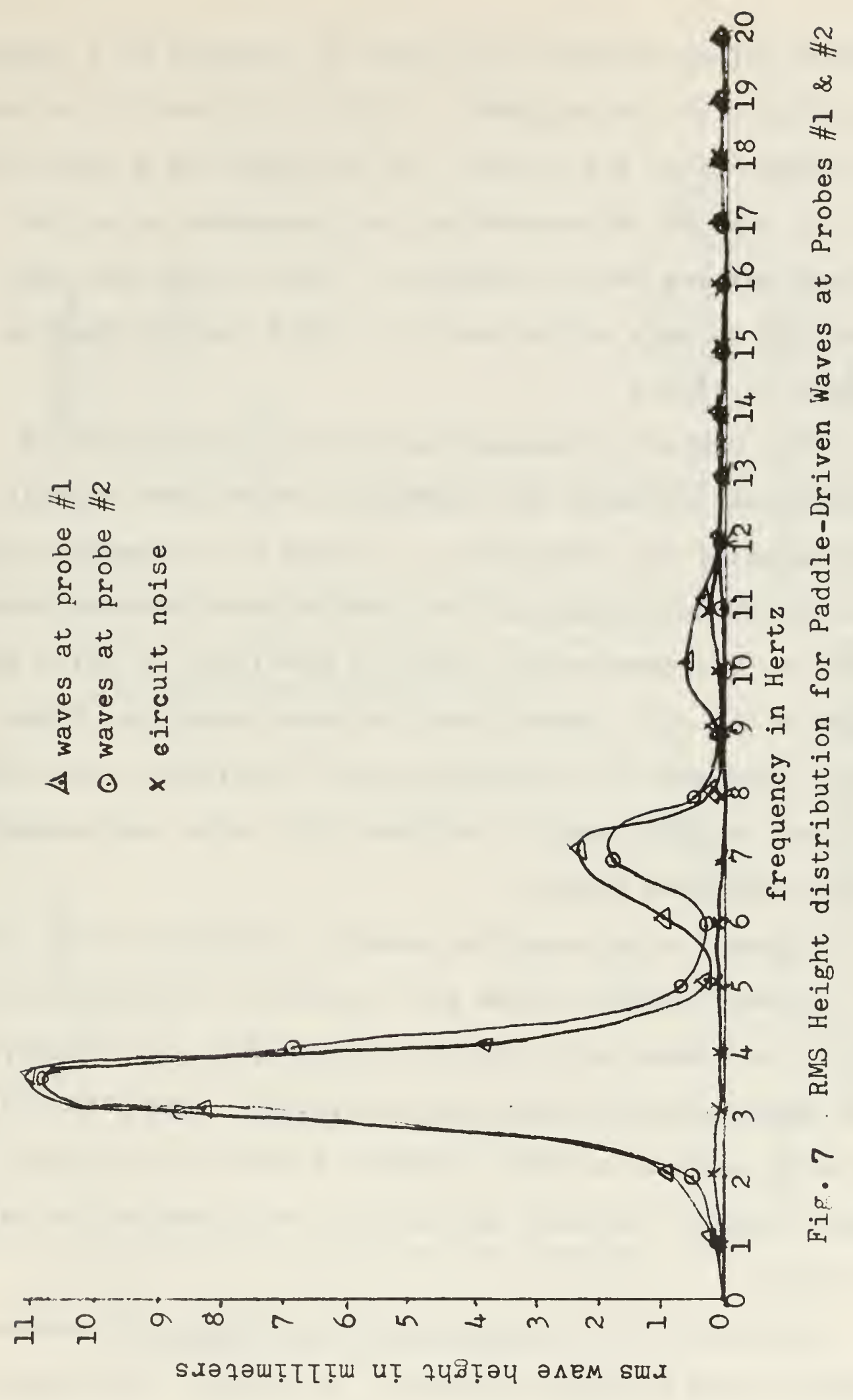


voltage passed through the filter as averaged by a smoothing circuit in the equipment. This value must be corrected for bandwidth of the filter (the analyzer has a selection of 3,10 and $50 \mathrm{~Hz}$ bandwidths) and converted to an rms voltage per one Hertz bandwidth. This voltage was then converted to wave height and it is this reading that is plotted in Figure 7.

This method of determining height distribution is particularly suitable for presenting broad band signals such as noise and turbulence. It does not, however, provide an accurate description of the surface wave spectra determined in this experiment, since it was found by using band widths of 10 and 3 Hertz that the wave energy was essentially independent of band width and, therefore, the wave analyzer voltage reading indicated the value corresponding to the true wave height.

Figure 7 also shows the spectral density of the circuit noise. Circuit noise was converted to equivalent wave height for comparison with the magnitude of wave energy. In most cases, circuit noise was negligible. The peak width of the wave spectra in these figures is due to the filter; in later figures, the wave spectra will be presented as spikes of energy.

Attenuation due to propagation distance was measured by comparing the two probe outputs. In Figures 8 through 14, wave height is plotted versus frequency at the two probe locations (1.2 meters apart) for the various frequencies 


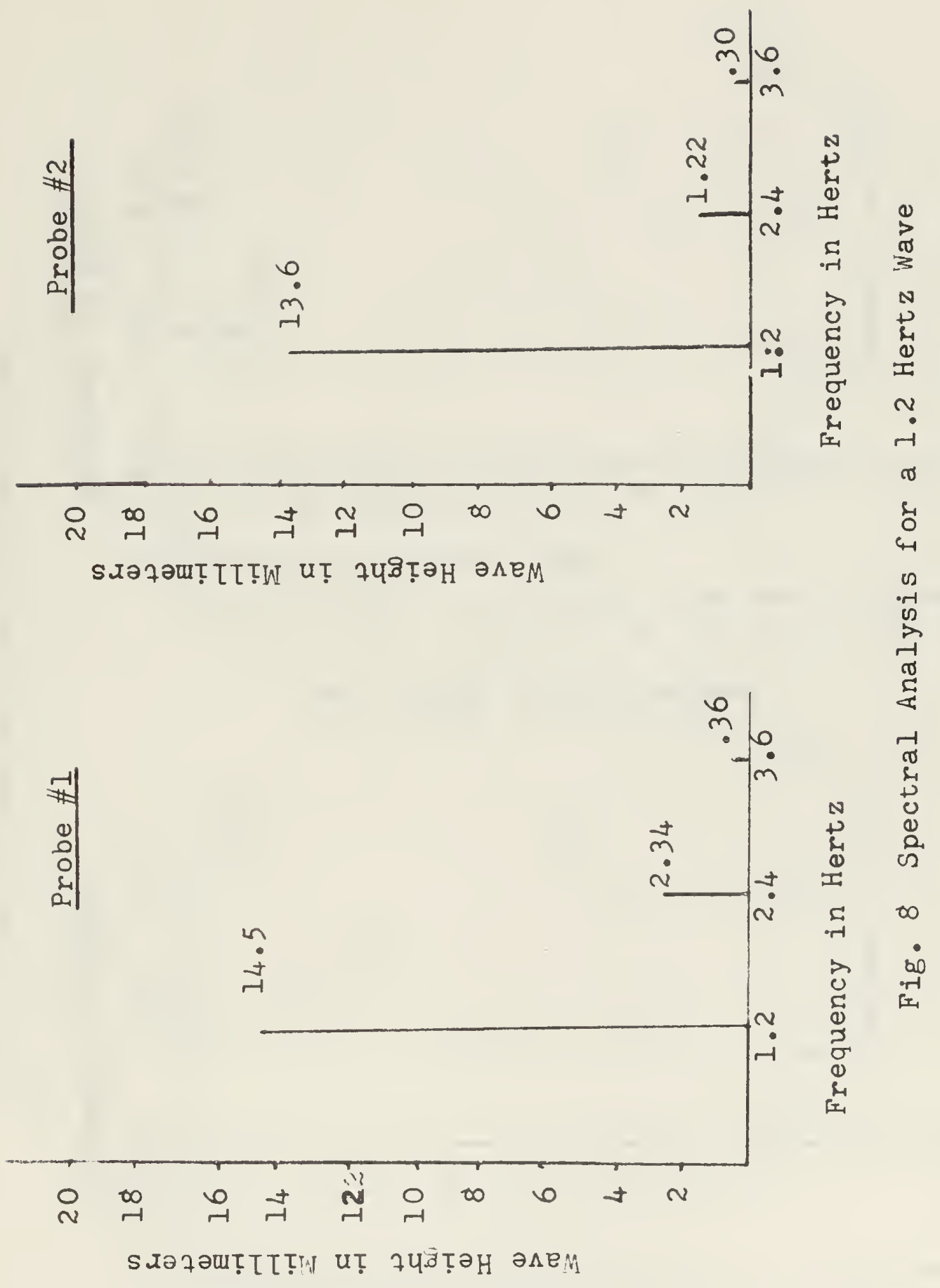


임

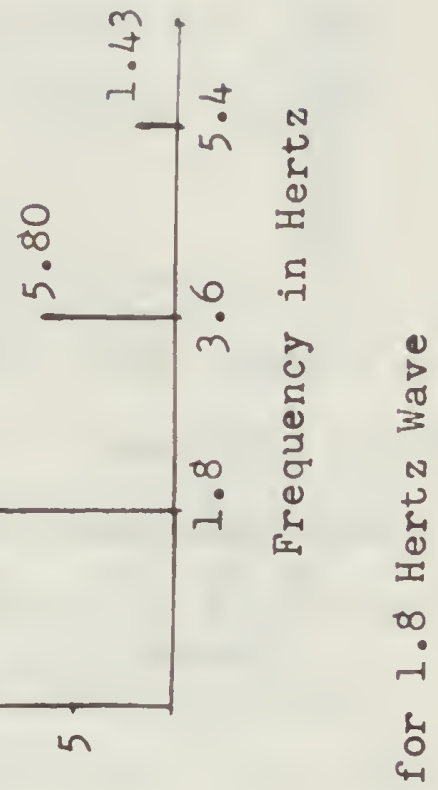

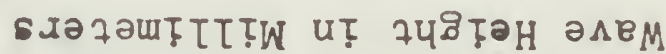

4
0
0
0
0
0.1

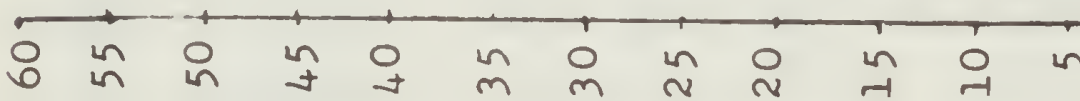

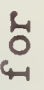

$\because$

$\stackrel{+}{2}$

$\infty$

-

on

先

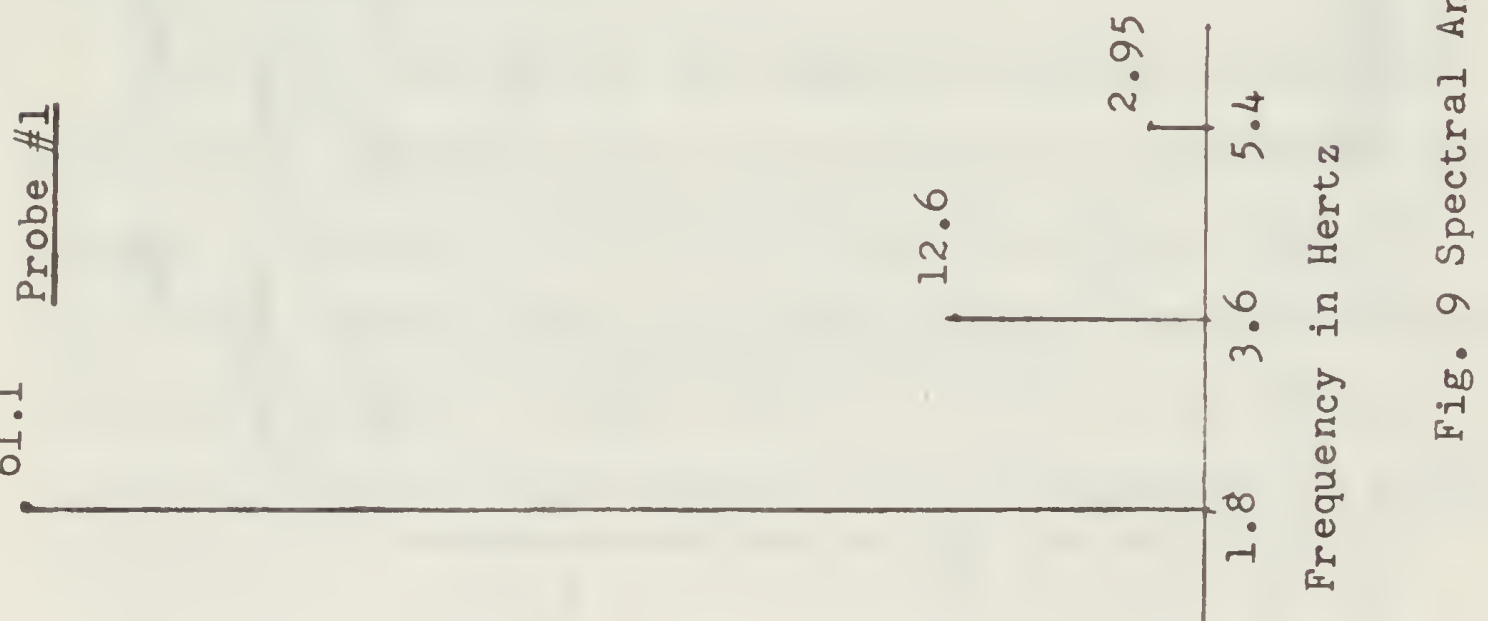

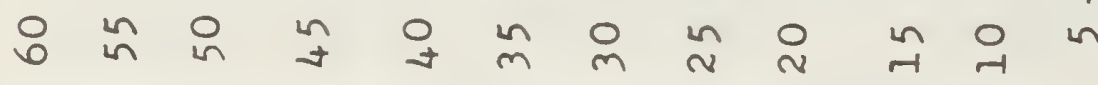

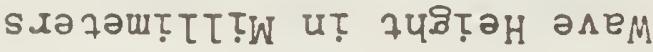




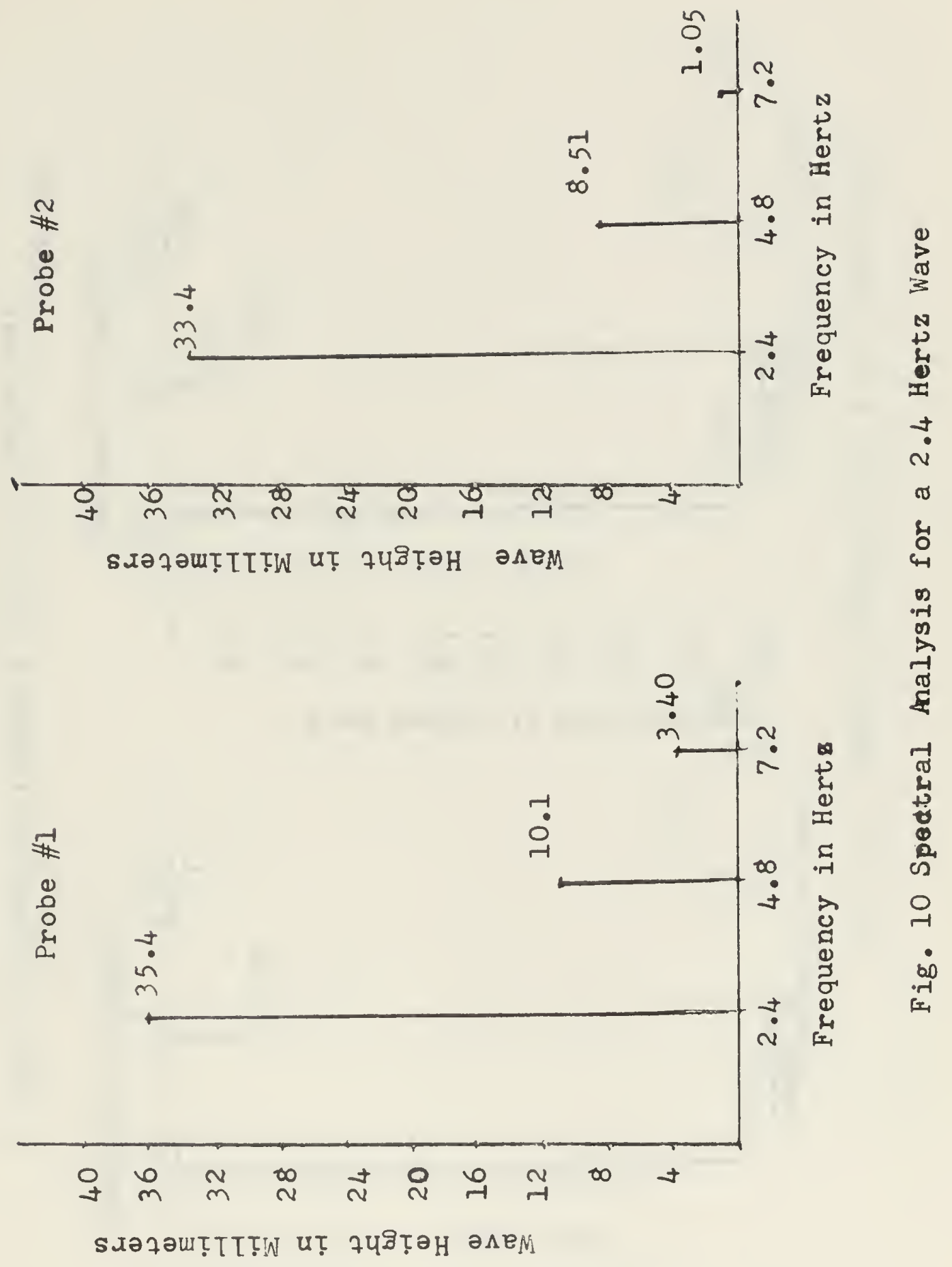




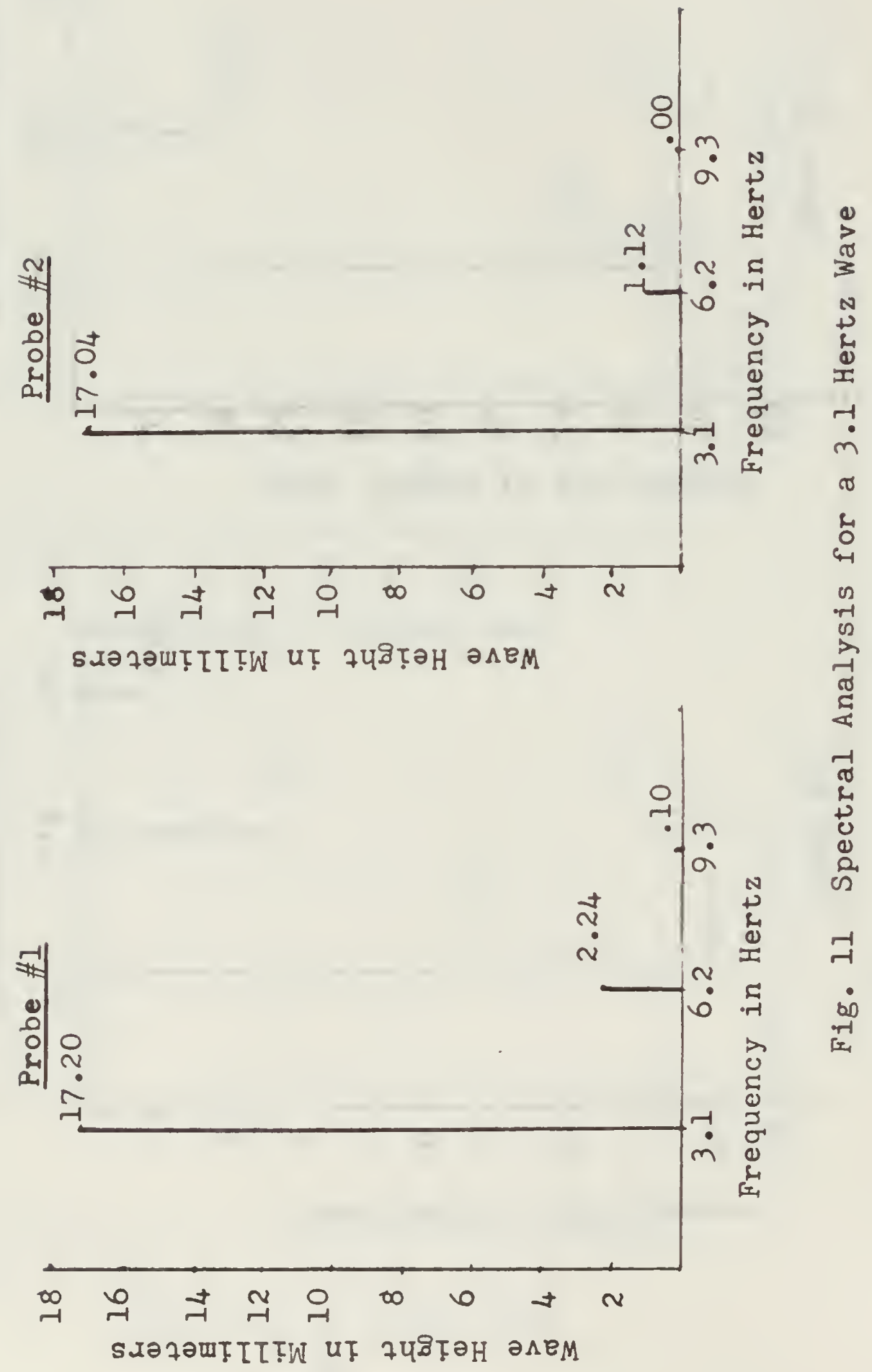




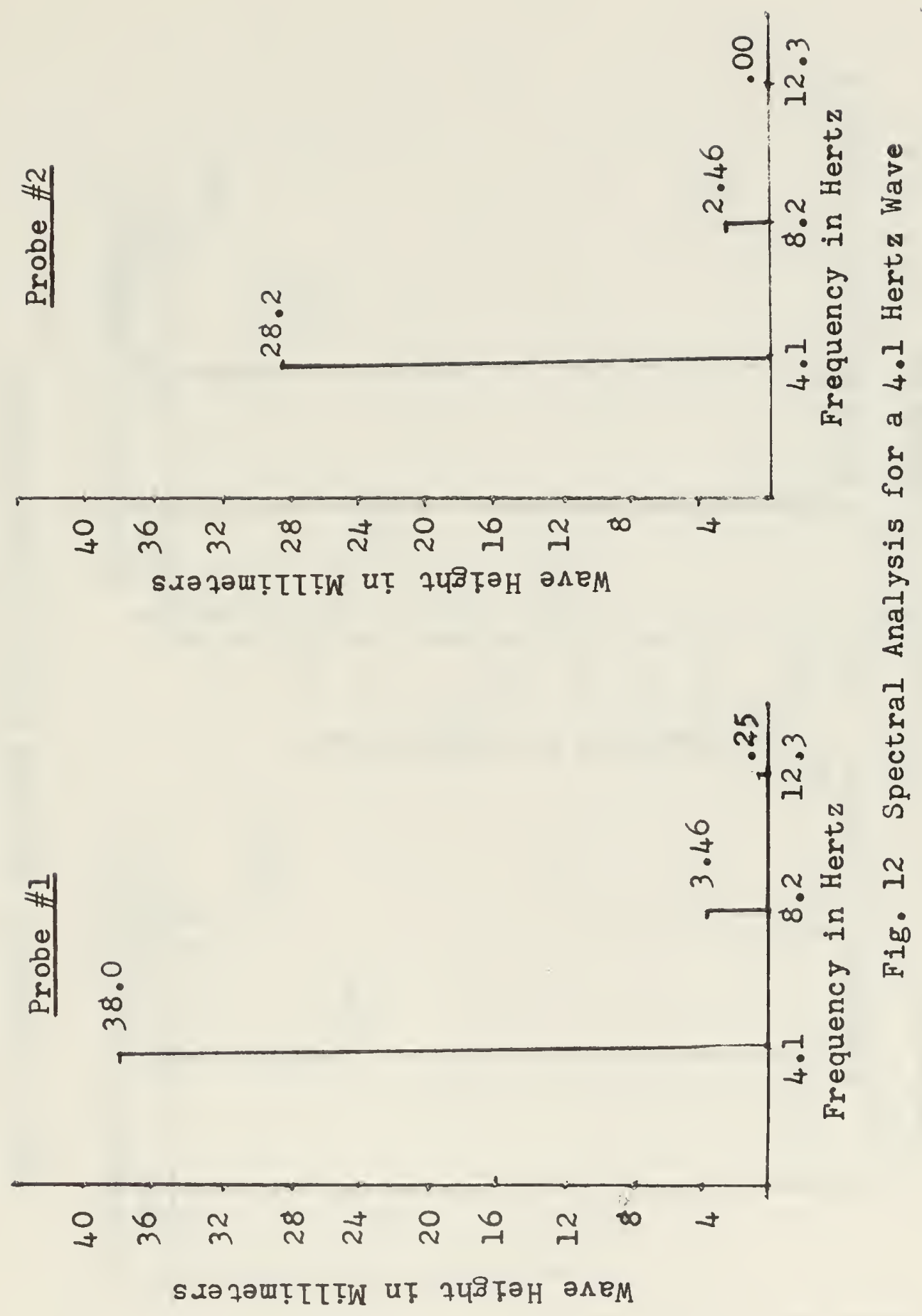




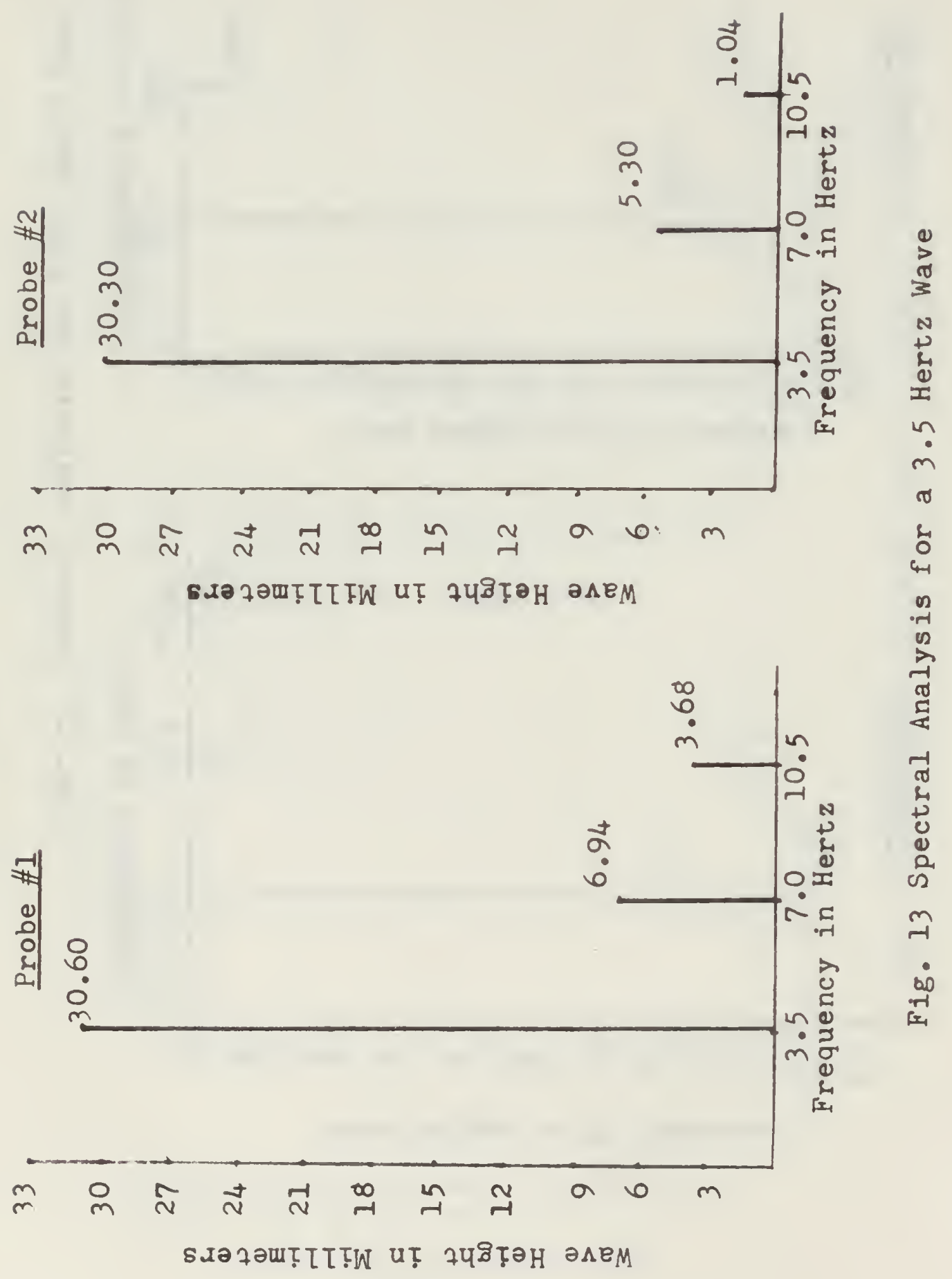




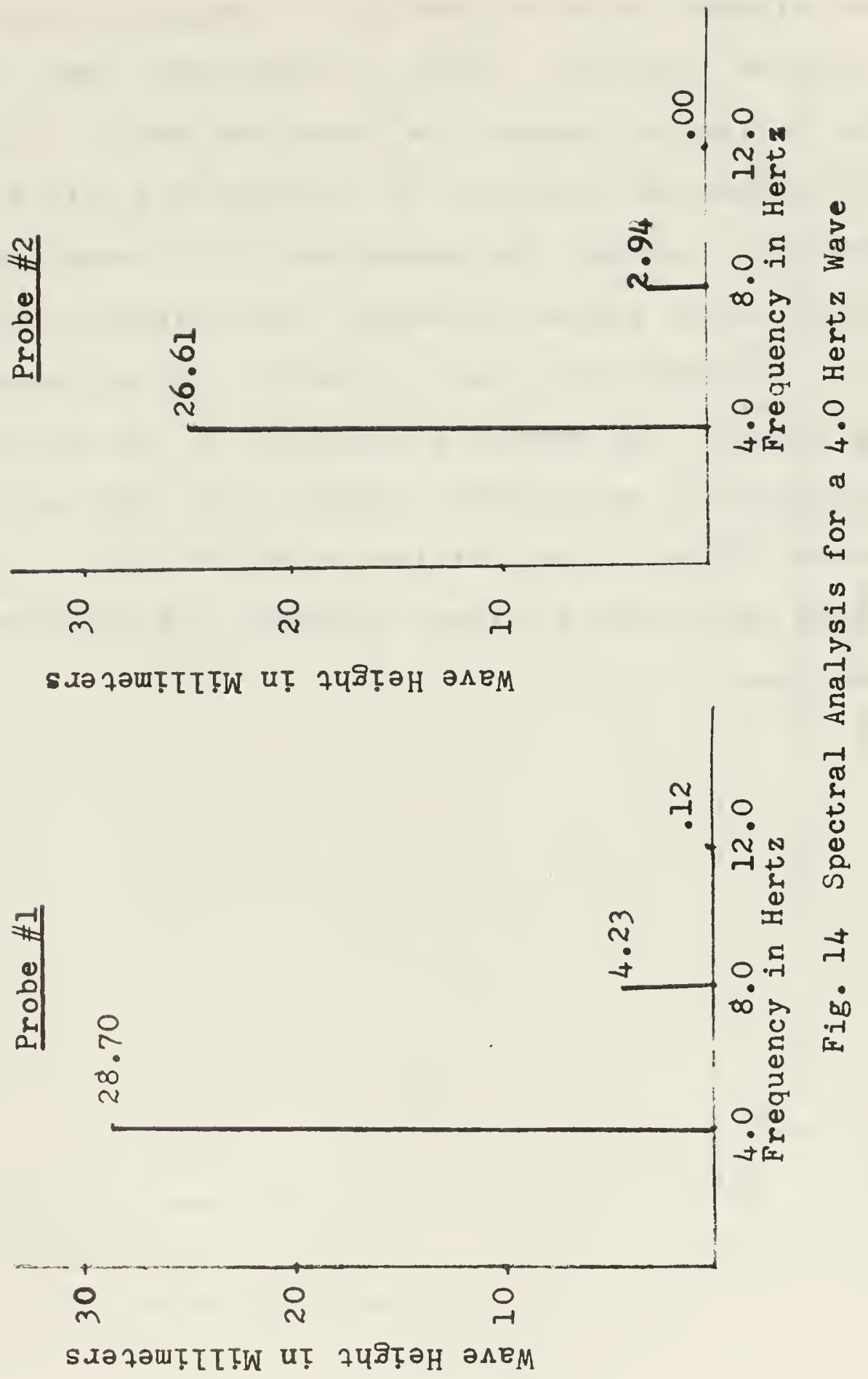


used is this experiment. Figure 15 shows the per cent wave attenuation as a function of frequency caused by this 1.2-meter distance. Figure 15 illustrates that attenuation due to distance between the probes was small. In most cases, the fundamental frequency of the waves was only slightly affected; however, the second and third harmonics were significantly reduced in height with distance, that is, the wave became more nearly sinusoidal with distance from the source. The greater attenuation of the high-frequency components is as expected; however, the large amount of scatter in the values obtained makes it difficult to assign a good relationship between frequency and attenuation in this case. 


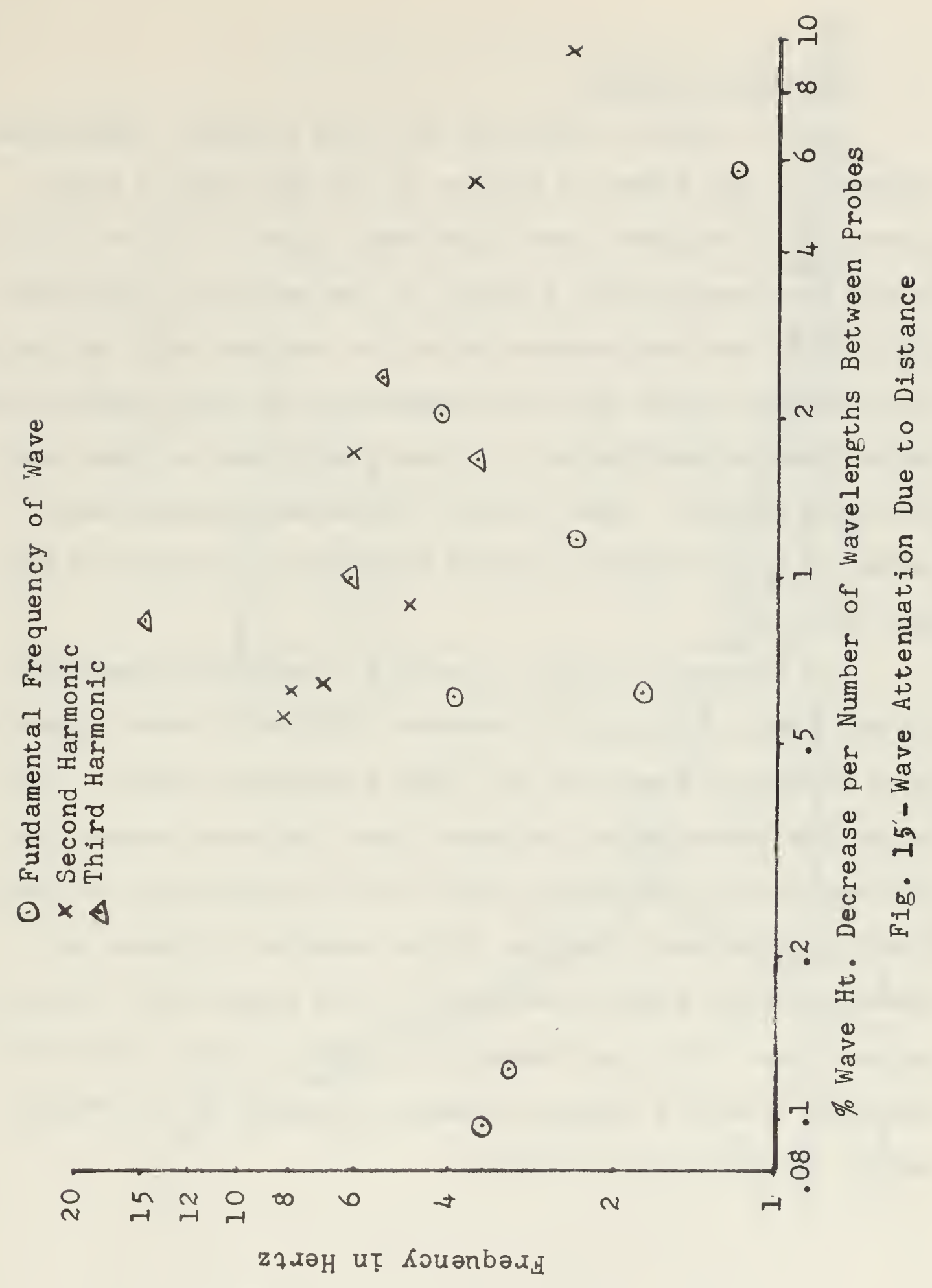




\section{Turbulence Spectra}

Typical spectra measured with the constant temperature anemometer are shown in Figure 16 for the case of waves, waves and turbulence, and turbulence alone. The velocities shown were measured at a point in the center of the turbulent zone, two centimeters below the surface with the probe in a position such that the anemometer was most sensitive to velocities perpendicular to a vertical plane in line with the wave crests. Other similar turbulence spectra were measured at six equally-spaced positions at depths of one and three $\mathrm{cm}$.

The drawbacks noted in section 4 make interpretation of the spectra difficult; however, Figure 16 shows significant turbulent energy at all wave frequencies used. The curve for waves alone indicated that the probe sensed the orbital velocities of the wave and its harmonics, and that the high frequency portion of the spectrum of waves and turbulence was almost identical to the spectrum of turbulence alone. The low-frequency portion of the turbulence spectrum showed a marked increase in energy at the fundamental frequency of the wave. 


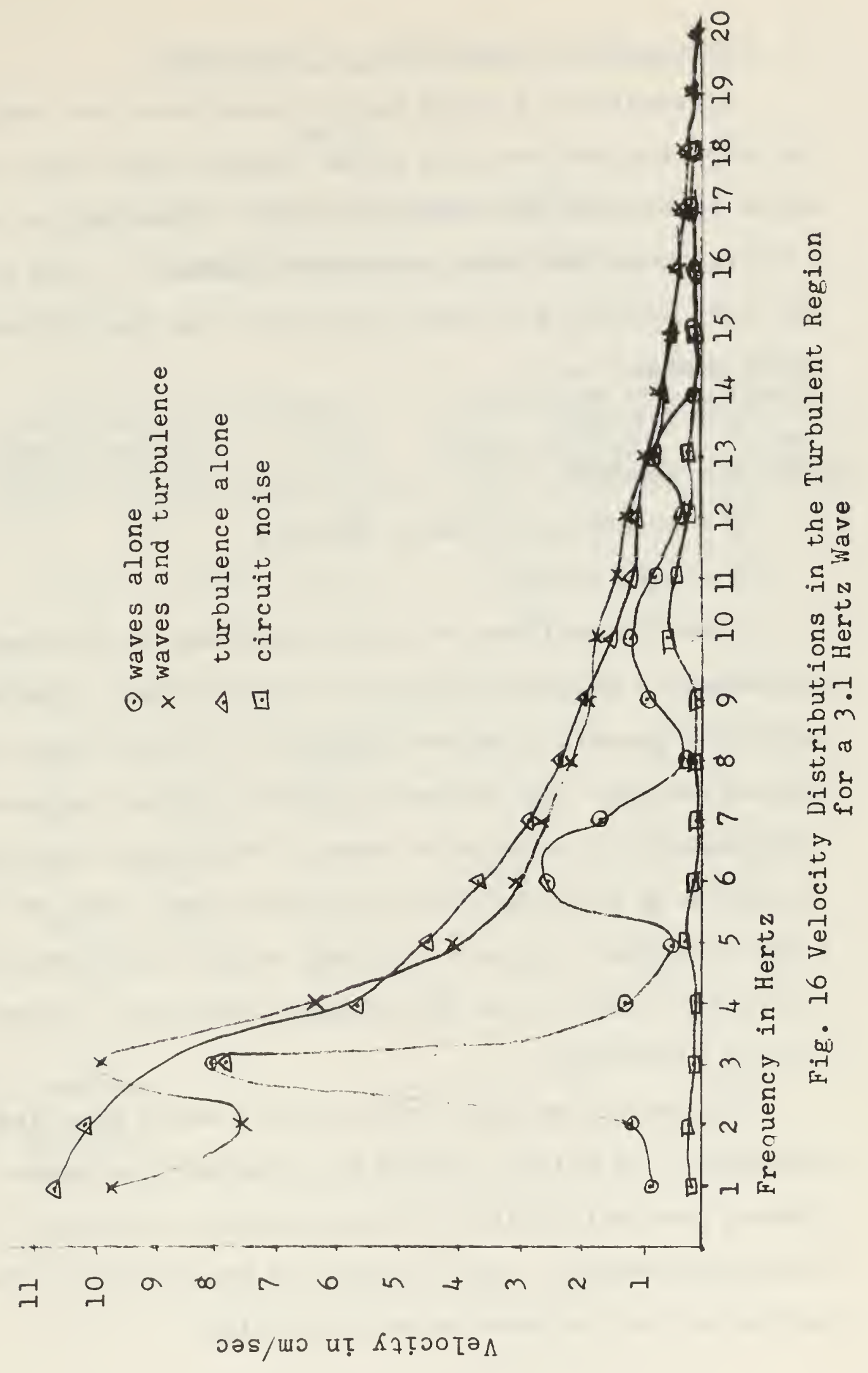


5. Attenuation of Waves due to Turbulence

Attenuation of waves due to turbulence was determined by comparing the two wave probe outputs which were recorded while turbulence was being generated. Some typical results of this comparison are presented in Table 1. Wave energ: per unit surface area was calculated from the following relationship:

$$
\begin{aligned}
& \mathrm{E}=1 / 8 \mathrm{dgH}^{2} \\
& \mathrm{~d}=\text { density } \\
& \mathrm{g}=\text { acceleration due to gravity } \\
& \mathrm{H}=\text { wave height }
\end{aligned}
$$

Other comparisons of attenuation due to turbulence are shown in Figures 17 to 23. Figure 24 is a plot of percent attenuation versus frequency on a log-linear graph. The points which are marked by dashed circles represent measurements of waves which were of sufficient wavelength to undergo a shoaling effect as they passed over the turbulence generator (in runs with the false bottom removed). The points that fall on the straight vertical line were completely attenuated.

Because of the additional effects which shoaling might introduce, the points circled by a dashed line cannot be considered good data points for quantitative turbulent attenuation measurements. They do indicate qualitatively that attenuation is less at lower wave frequencies. 


\section{TABLE 1}

TYPICAL VALUES OF ENERGY LOSSES

(Energy density in Ergs/ $\mathrm{cm}^{2}$ )

Loss Due to

Loss Due to Distance Turbulence and Distance

Freq. Energy Density

\% Loss

Energy Density

\& Loss

(Hz) Probe\#1 Probe\#2 of Energy Probe\#l Probe\#2 of Energy

3.1372

356

.43

347

18.1

94.8

* 6.2

5.63

1.55

72.6

45.4

.24

99.6

$\star * 9.3$

.01

.00

.04

.00

$3.5 \quad 1148$

1127

.18

1750

38.1

98.0

* 7.0

59.3

34.5

40.8

60.2

.00

$\star * 10.5 \quad 16.5$

1.31

92.2

1.59

.00

$4.0 \quad 1018$

870

14.5

986

60.00

93.9

* 8.0

22.1

10.6

52.0

21.3

.00

$* * 12.0$

.02

.00

84.8

$.00 \quad .00$

* second harmonic

** third harmonic 


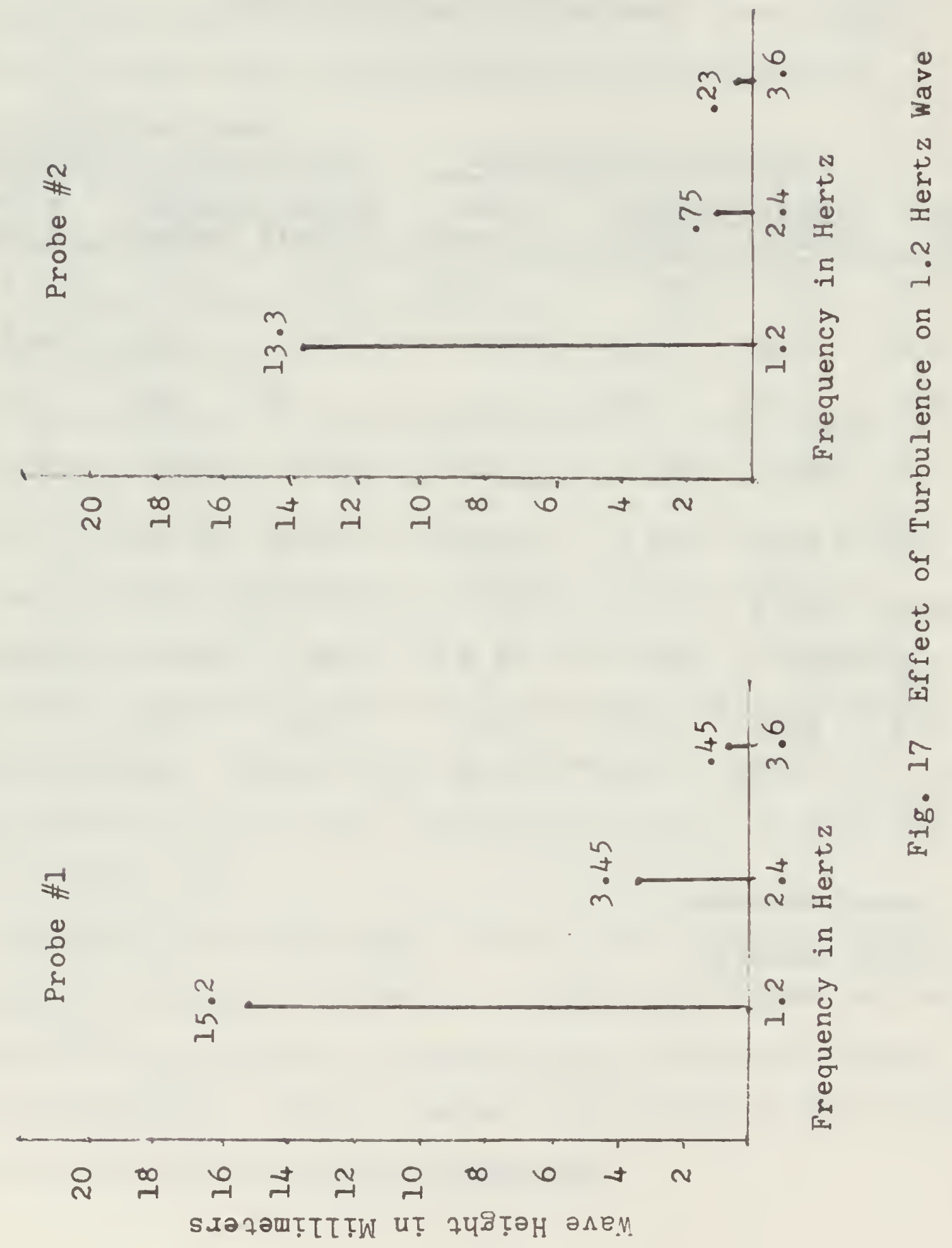




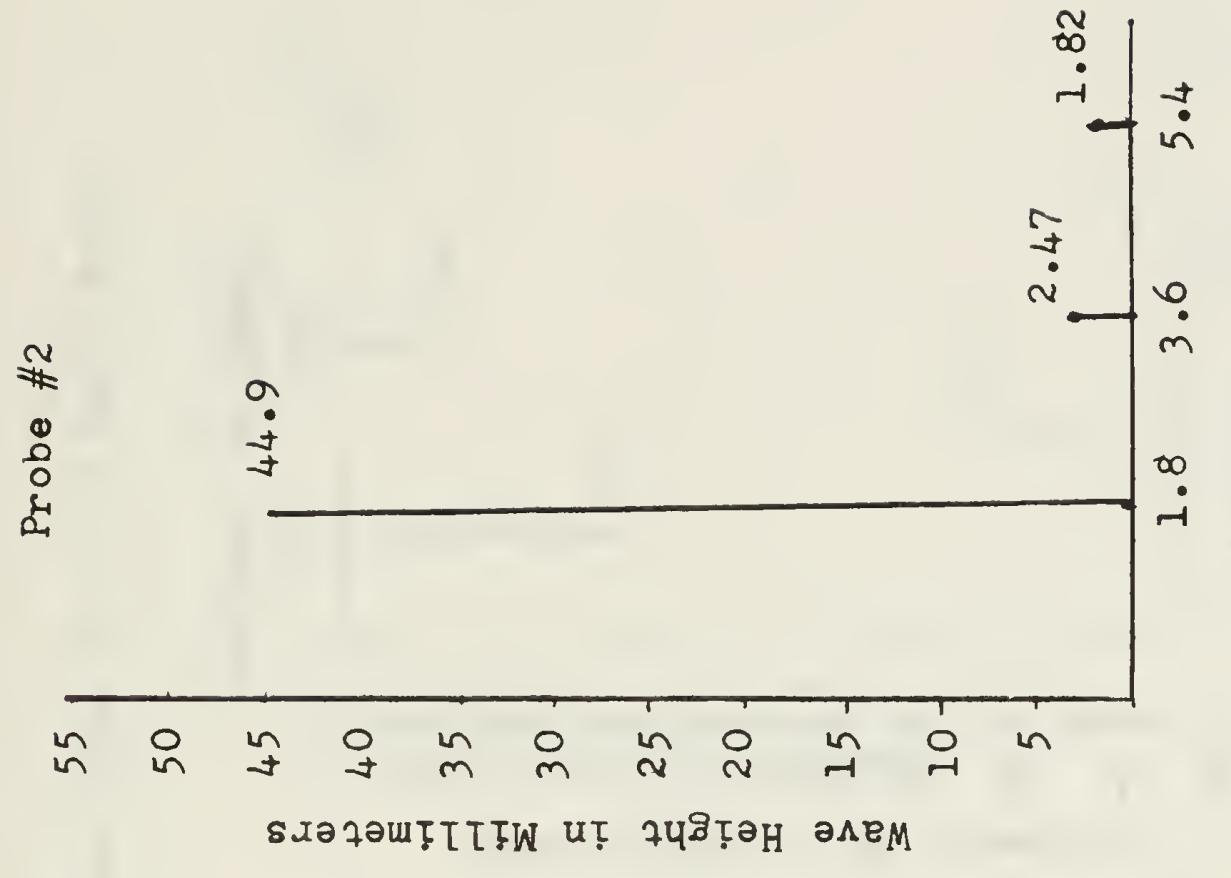

$\begin{array}{ll}0 & 0 \\ 0 & 0 \\ 0 & 0 \\ 0 & 3\end{array}$

.

구

도

己े

म

¿

0

फ

-1
0
0
0
2
0
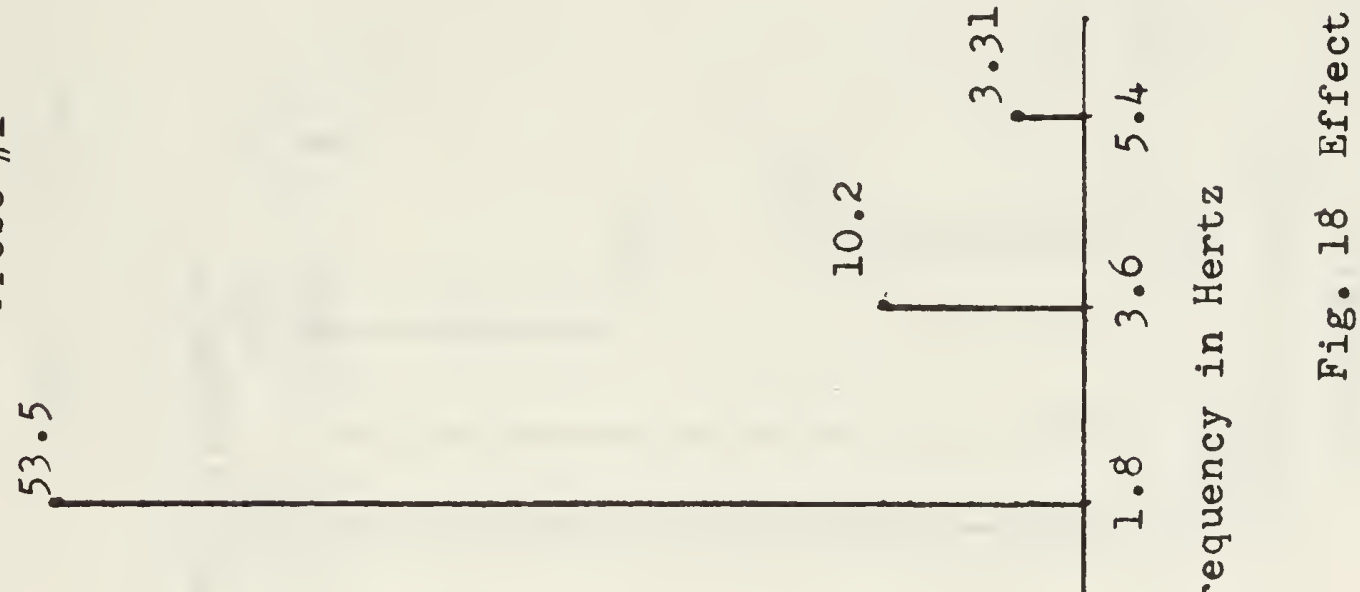

$\stackrel{N}{i} \infty$

का i $\quad$ in

D્

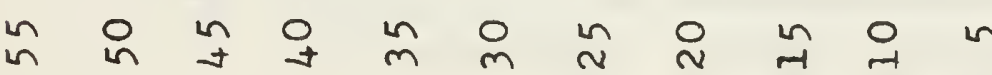

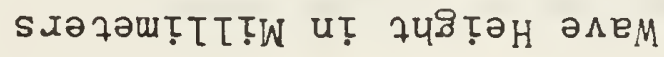


\begin{tabular}{l}
$\sim$ \\
\multirow{2}{*}{} \\
0 \\
0 \\
0 \\
2 \\
0
\end{tabular}
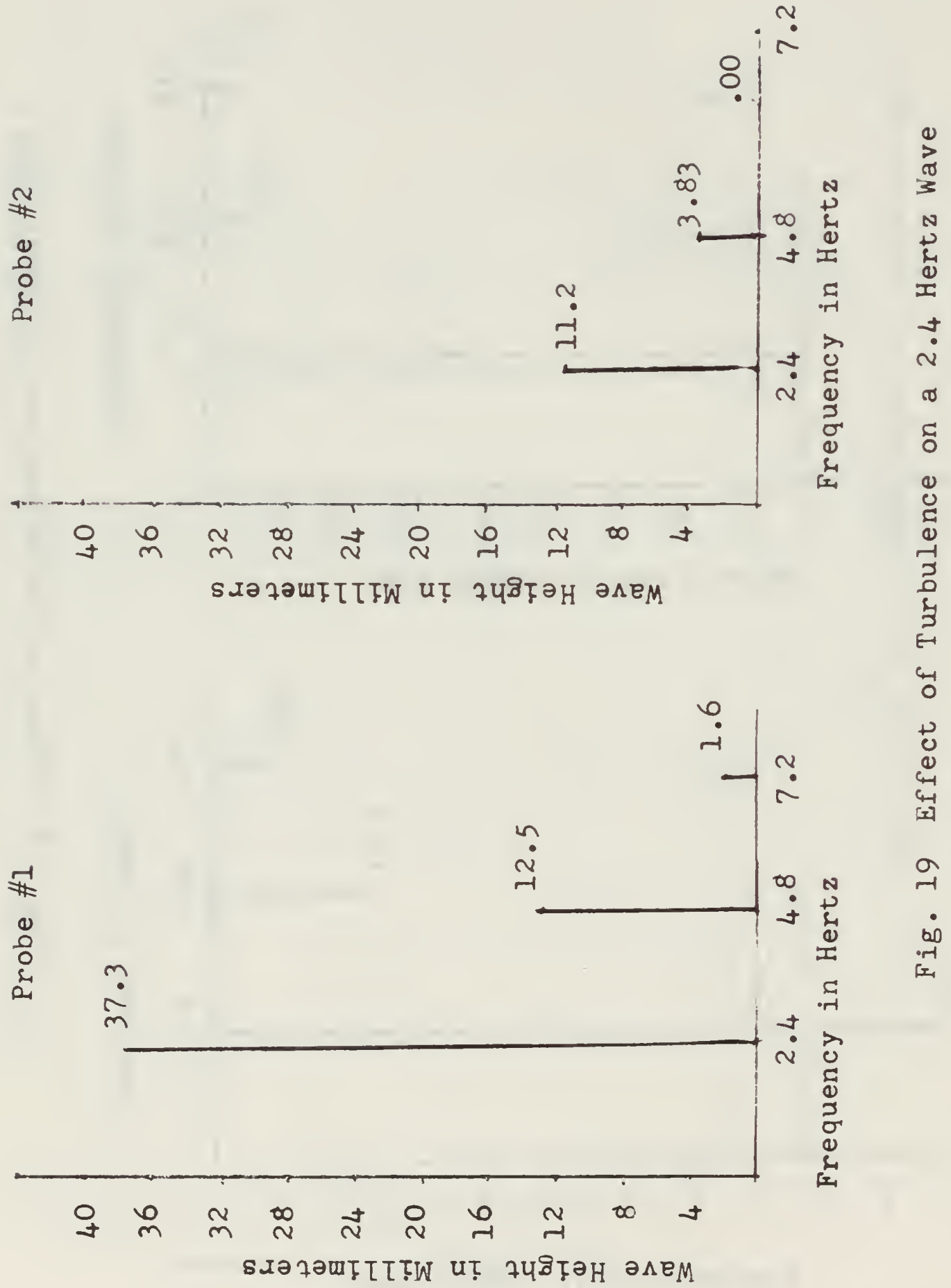
$\sim$
0
0
0
0
0.1
0.1

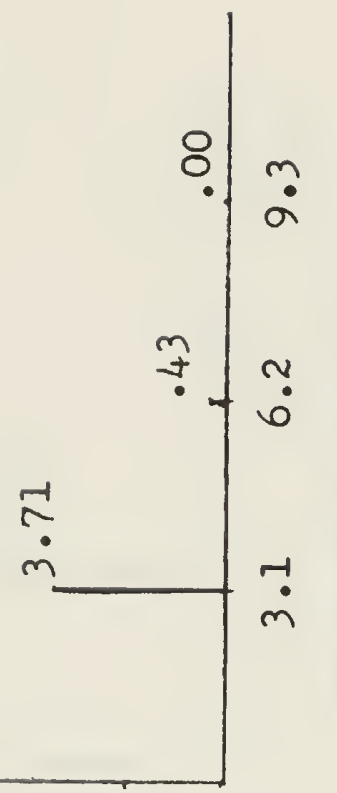

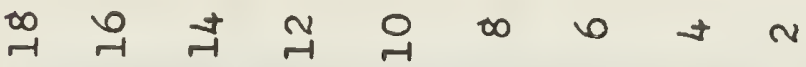

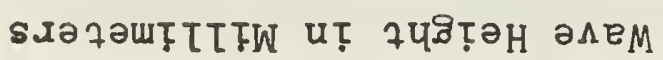

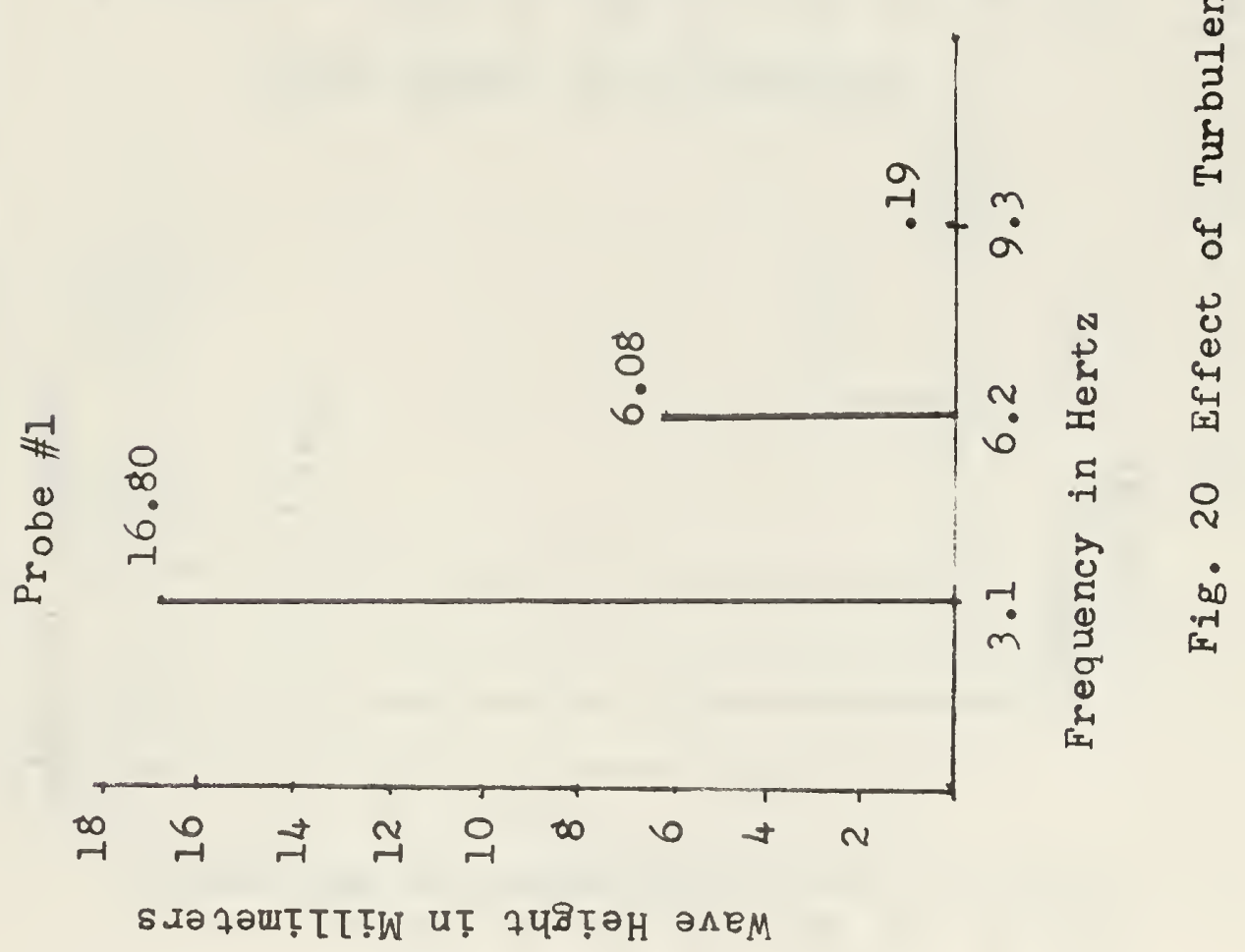


0
0
0
0
0
0
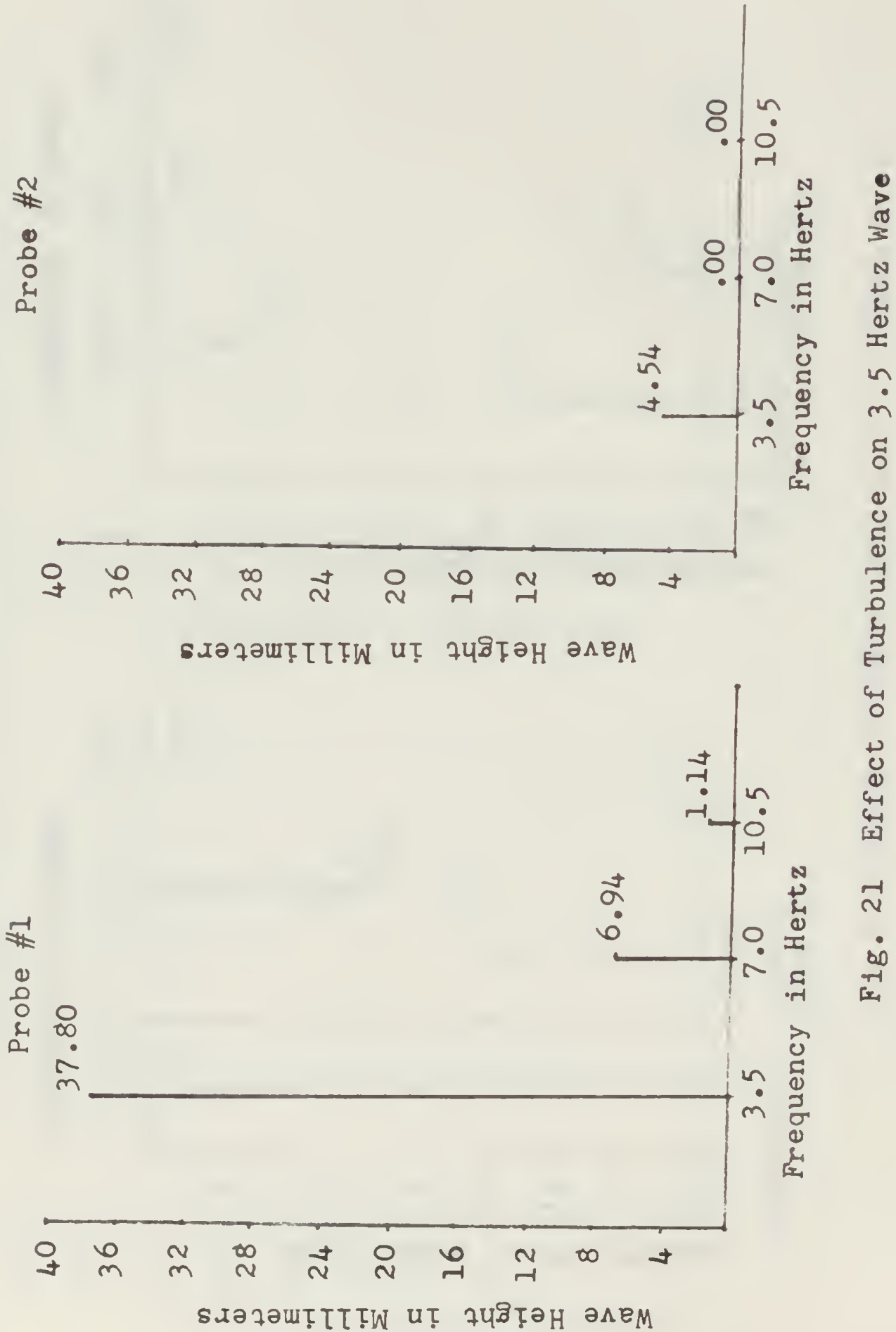


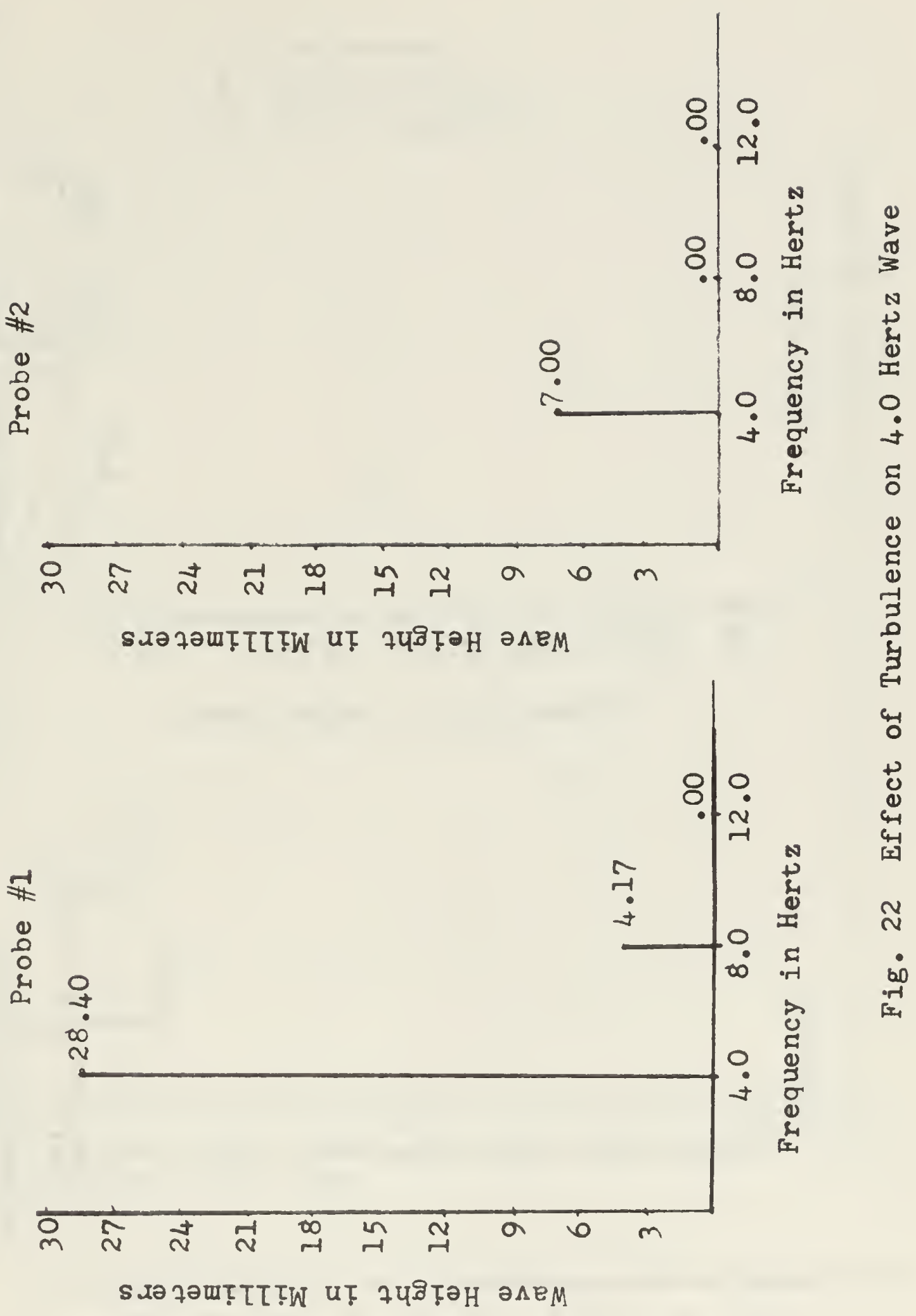




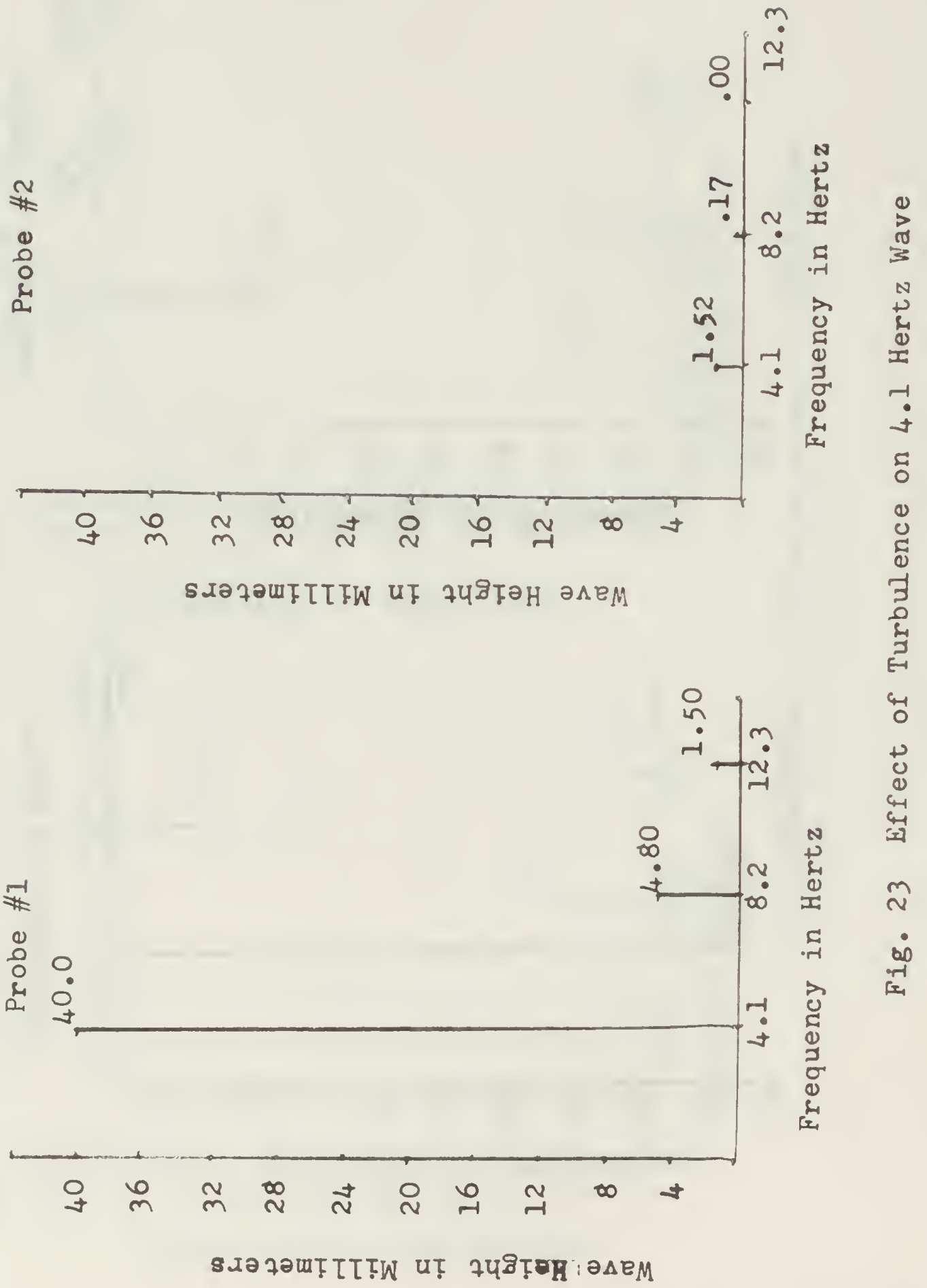




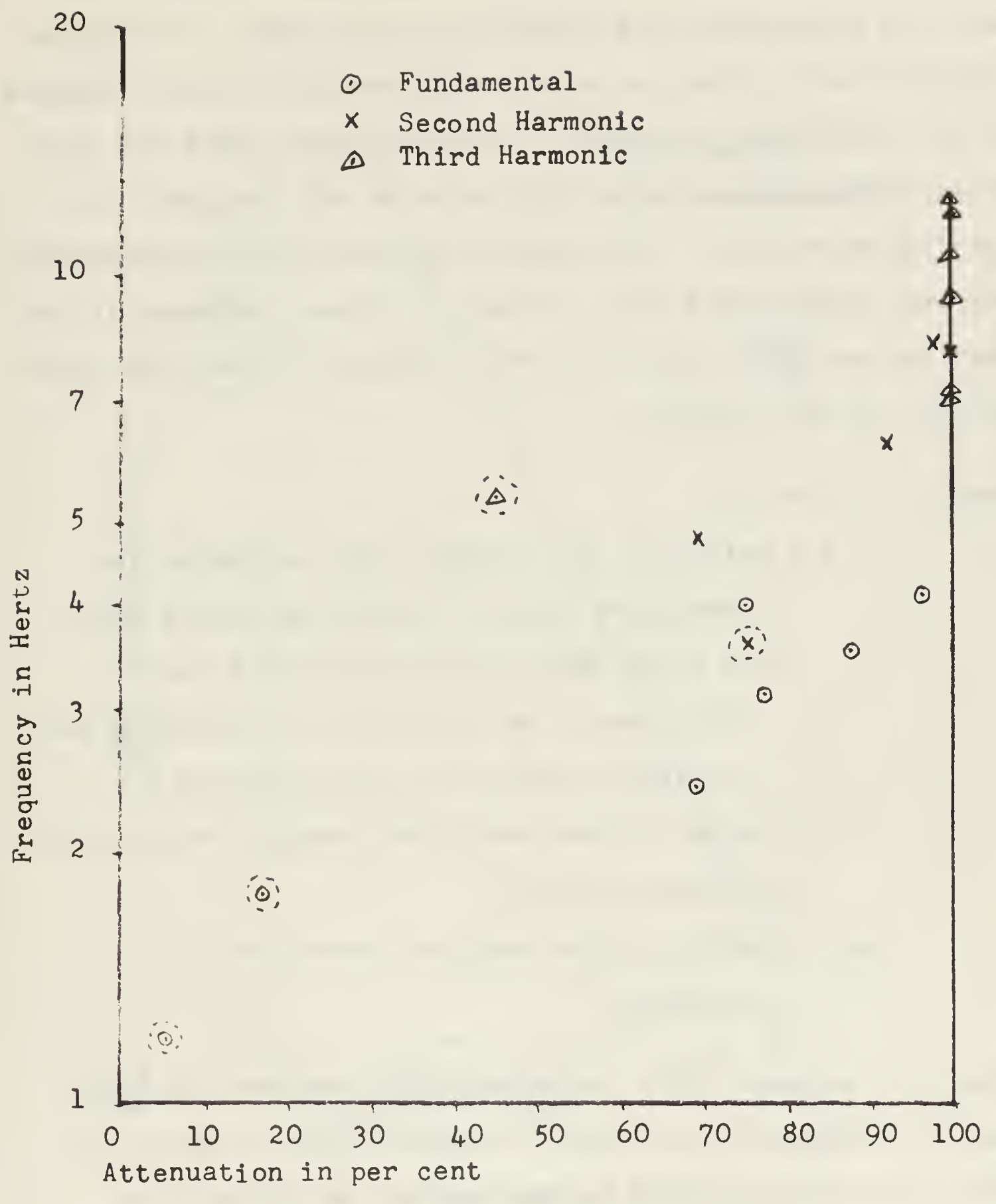

Fig. 24 Percent Wave Attenuation due to Turbulence 
The length of the turbulent region used in this experiment was essentially the same for all data runs. The waves, however, were of various wavelengths and thus, their exposure to the turbulence differed. A high-frequency wave had more wavelength exposed to the turbulence at any one time than a low-frequency wave. This unequal exposure to the turbulence has been compensated for in Figure 25 where frequency is the abscissa and $\frac{\Delta h / h}{\Delta x / L}$, the fractional change of height per wavelength, is the ordinate.

where:

$$
\begin{aligned}
H= & h-h_{1} \\
h= & \text { height of the incident wave corrected for } \\
& \text { attenuation due to distance by multiplying } \\
& \text { the value obtained at the first probe by } \\
& (1-b) \text { where } b \text { is the percent attenuation due } \\
& \text { to distance alone for that frequency. } \\
h_{1}= & \text { height of the wave after passing through the } \\
& \text { turbulent region. } \\
\Delta x= & \text { length of the turbulent zone, and } \\
L= & \text { wavelength }
\end{aligned}
$$

Figure 25 suggests that the relationship between $\log \frac{\Delta h / h}{\Delta x / L}$ and $\log$ (frequency) is linear. Assuming this to be so, a least squares fit to the points results in a line given approximately by the equation:

$$
\log \frac{100 \Delta h / h}{\Delta x / L}=-\frac{5}{3} \log f+2.10
$$




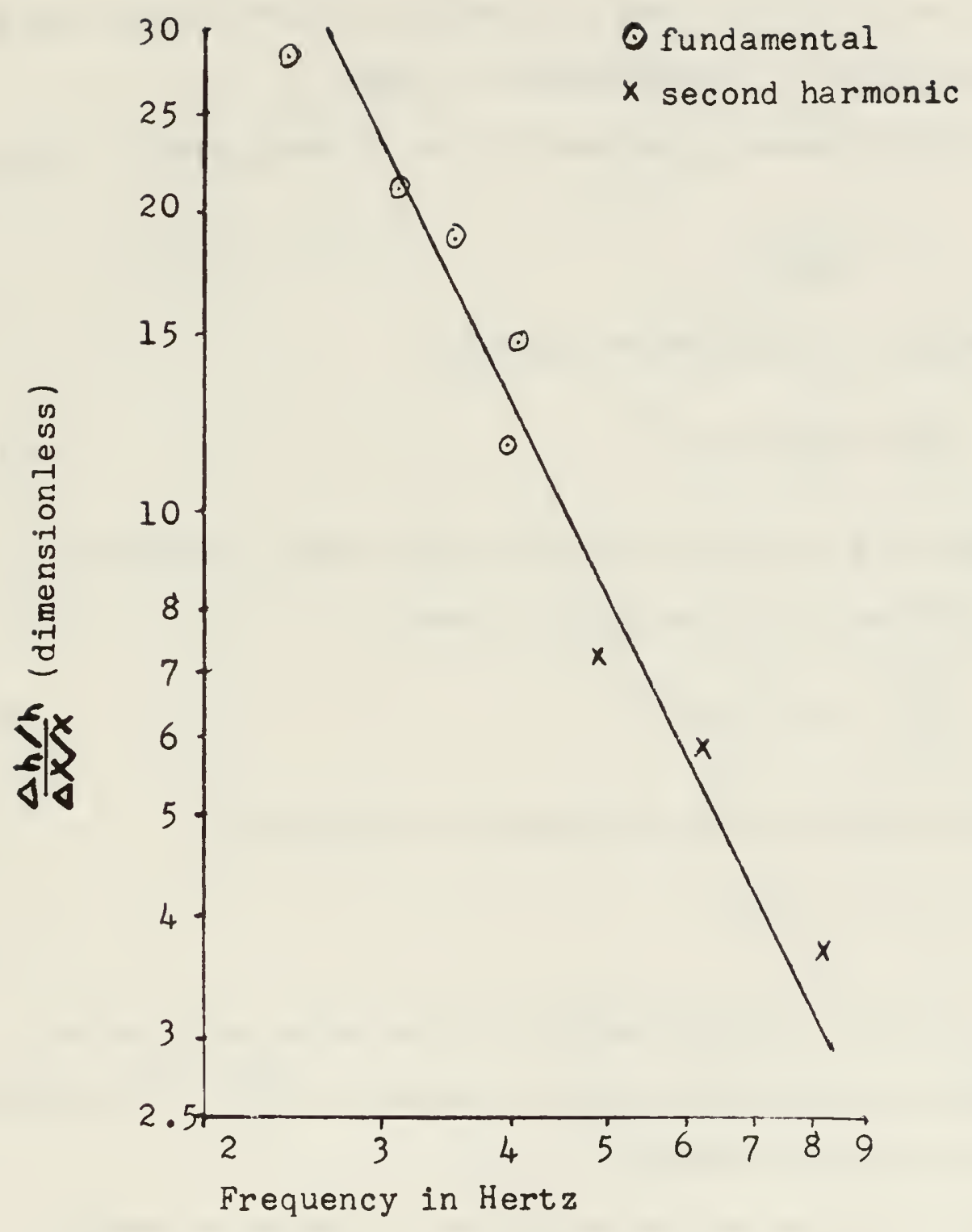

Fig. 25 Attenuation of Waves Due to Turbulence Plotted as a Function of Number of Wavelengths in the Turbulent Region 
which can be written

$$
\frac{\Delta h}{h}=\frac{\Delta x}{L} K f-\frac{5}{3}
$$

where $K$ has units of time to the-five-thirds power and a numerical value of approximately 1.26 .

If the waves are assumed to be in deep water, then:

$$
L=\frac{g}{2 \pi f^{2}}
$$

and equation (2) can be written as:

$$
\frac{\Delta h}{h}=\frac{\Delta x}{g} 2 \pi K f^{1 / 3}
$$

If $\Delta h$ and $\Delta x$ are allowed to become very small, equation can be written in differential form:

$$
\frac{d h}{h}=d x \frac{2 \pi K}{g} f^{1 / 3}
$$

Integrating both sides of equation (4) yields:

$$
h=h_{0} e^{-a x}
$$

where $h_{0}$ is the initial height of the wave and $a$ is an attenuation coefficient which is equal to $\frac{2 \pi k}{g} f^{l / 3}$, and has units of reciprocal length.

This relation may be expressed in terms of energy density as follows:

$$
E=\frac{1}{8} d g h^{2}
$$

where $\mathrm{d}$ is fluid density and $\mathrm{E}$ is energy per unit area. 
Substituting equation (5):

$$
E=\frac{1}{8} d g h_{0}^{2} \quad e^{-2 a x}
$$

or

where

$$
E=E_{0} e^{-2 a x}
$$

$$
E_{0}=\frac{1}{8} \mathrm{dgh}_{0} 2
$$




\section{Phase Shift in the Turbulent Zone}

The fundamental frequency of the wave trains experienced a phase shift upon passing through the turbulent region. This shift was not measured for second and third harmonics because of the limitations in the measuring technique.

Phase shift was measured by recording the output of both probes on a two-channel strip chart recorder. Waves alone were measured initially; the turbulence generator was then turned on and the outputs of the two probes were compared with respect to their phase relationship both before and after passing through turbulence.

Firure 26 is a plot of frequency versus phase shift and frequency versus phase shift per number of wavelengths passing through the turbulent region at any one time.

Figure 26 shows that at the lowest frequency measured, the phase shift was negative. At higher frequencies the phase shift was positive and increased with frequency.

Assuming that the frequency of the waves remained constant as they travelled the length of the tank, the observed phase shift implies that both the wavelength and the phase speed of the waves changed as they passed through the turbulent region and that this phase change increased in magnitude with frequency. It was observed visually, particularly for the higher frequency waves, that as the waves entered the turbulent region, they steepened considerably at first and were then reduced in height and steepness in the 


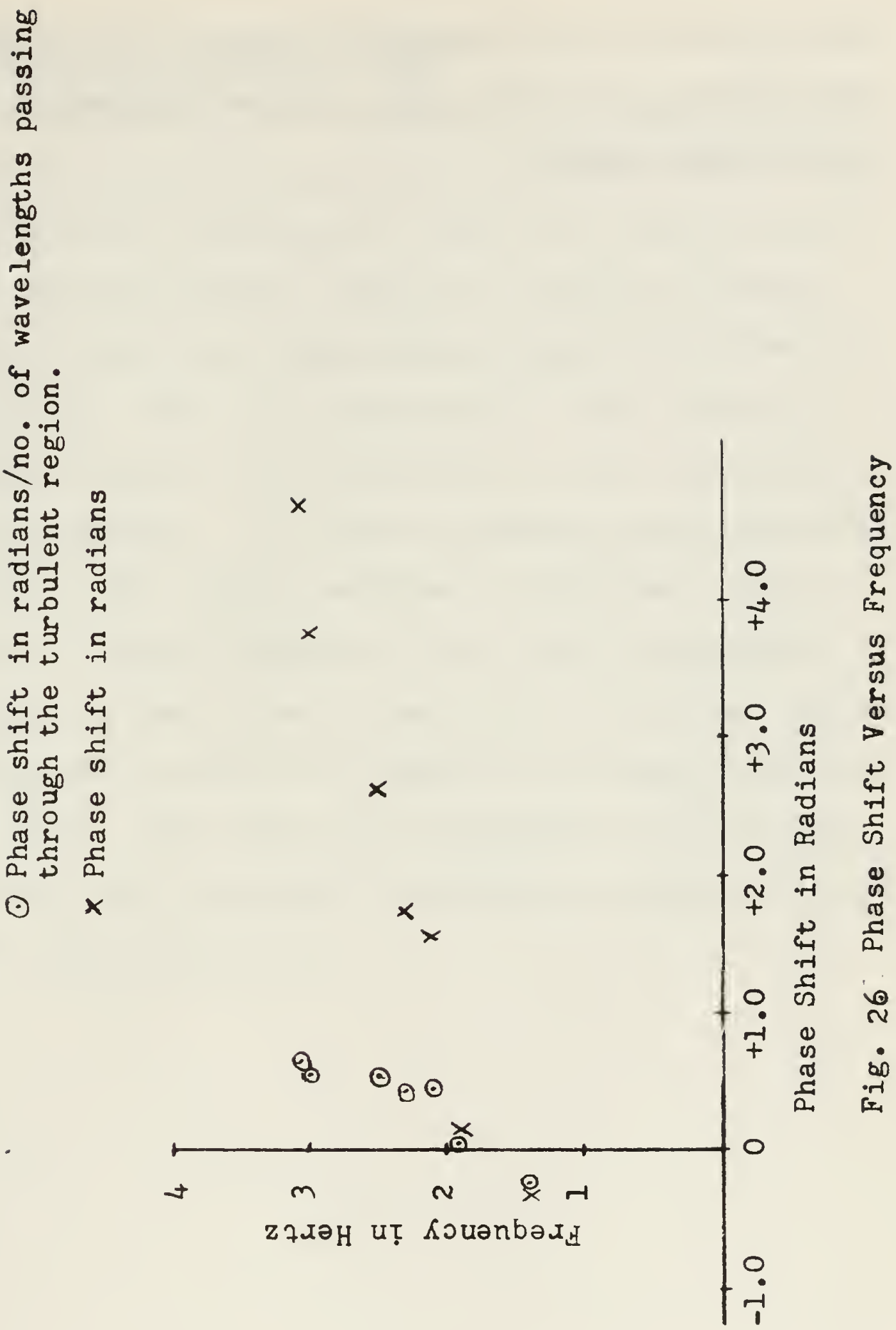


later portion of the turbulent region. It is uncertain in what manner, if at all, this observed steepening is related to the phase shift. 


\section{Attenuation of Wind-Driven Waves}

A model sea surface was generated with a small centrifugal blower, and measurements of surface spectra were taken with and without the turbulence. Figure 27, a plot of rms wave height versus frequency, shows the results of these measurements. The entire water surface was in the blower's generating area. Thus, the waves were not only affected by propagation distance and turbulence, but also by being in a region of generation. The figure indicates that the higher frequency waves were almost completely attenuated, while a small amount of energy remained in the lower frequencies. The difference in peak values between the undisturbed spectra at probes one and two shows the effect of a longer fetch for the second probe. The blower also generated many high frequencies which were attenuated by propagation distance before they reached the second probe. 


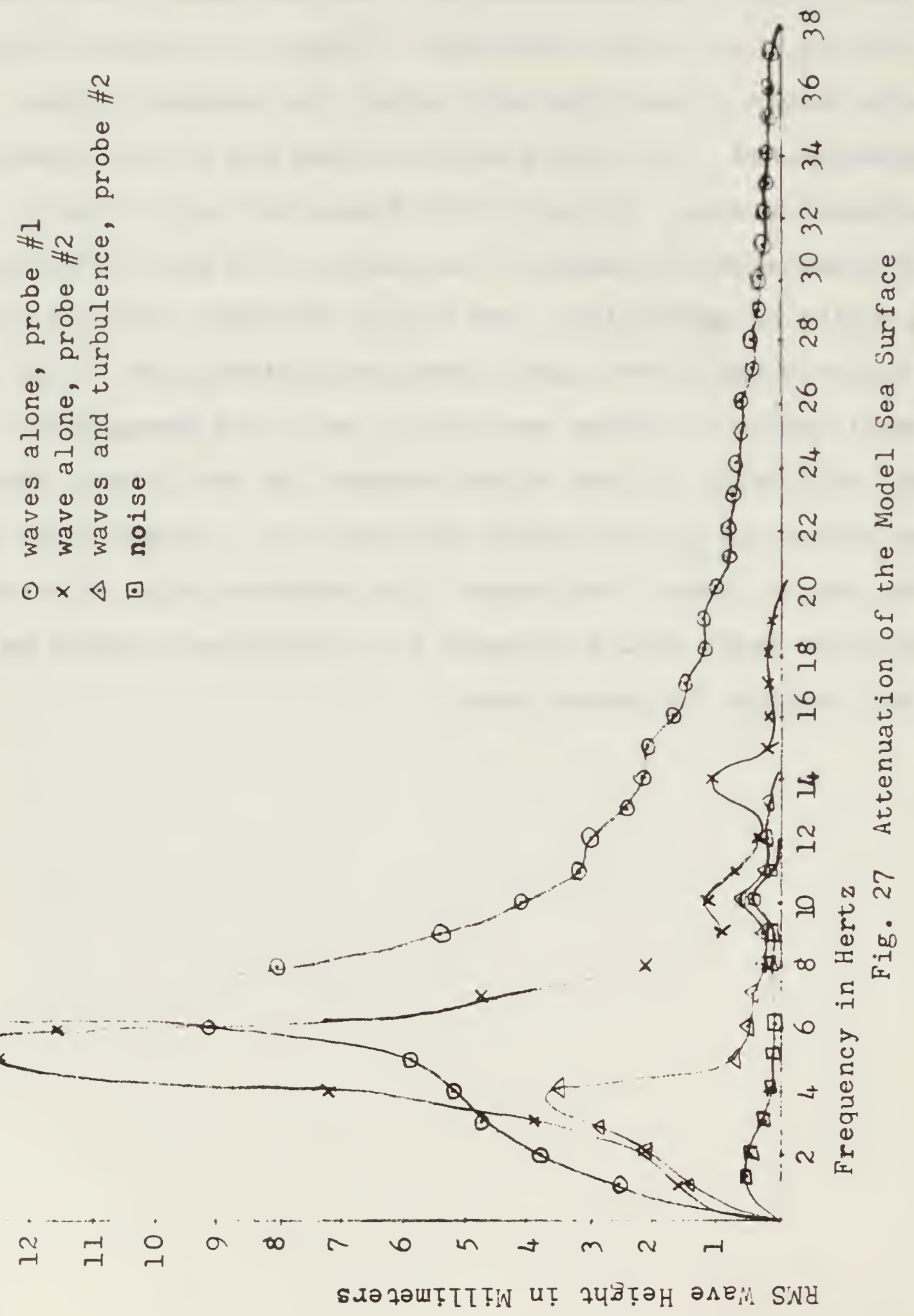




\section{Summary and Conclusions}

This experiment showed that underwater turbulence had the following effects on surface waves:

1) Wave height decreased as a result of attenuation by turbulence for all frequencies measured (1.2 to $12.3 \mathrm{~Hz}$ ) according to the formula

$$
h=h_{0} e^{-a x}
$$

where $a$ is an attenuation coefficient equal to $\frac{2 \pi k}{g} f^{1 / 3}$

2) The waves studied were shifted in phase by turbulence; below 1.5 Hertz, this shift was negative and became positive above 1.5 Hertz.

3) Measurements using a model sea surface indicate, qualitatively, that a continuous spectrum of waves experiences attenuation in much the same manner as the nearly sinusoidal waves of this experiment. 


\section{BIBLIOGRAPHY}

1. Groen, P. On the Behavior of Gravity Waves in a Turbulent Medium, with Application to the Decay and Apparent Period Increase of Swell. StaatsdrukkerijEn Uitgeverijbedrijf/'S-Gravenhage, 1954 .

2. Barnett, T. P. On the Generation, Dissipation, and Prediction of Ocean Wind Waves, Journal of Geophysical Research, Vol. 73, No. 2, January 1968. 
No. Copies

1. Defense Documentation Center

Cameron Station

Alexandria, Virginia 22314

2. Library

Naval Postgraduate School

Monterey, California 93940

3. Naval Weather Service Command

Washington Navy Yard

Washington, D. C. 20390

4. Dr. H. Medwin

Department of Physics

Naval Postgraduate School

Monterey, California 93940

5. Director, Naval Research Laboratory

Attn: Tech. Services Info. Officer

Washington, D. C. 20390

6. Commander Naval Ships Systems Command

Attn: Code OOVIK

Washington, D. C. 20390

7. Prof. N. E. Boston

Department of Oceanography

Naval Postgraduate School

Monterey, California 93940

8. Dr. 'i'. Green IJI

Department of Oceanography

Naval Postgraduate School

Monterey, California 93940

9. W. Smith

Departricent of Physics, Room 022

Naval. Pustgraduate School

Monterey, California 93940

10. Department of Oceanography Code 58

Naval Postgraduate School

Monterey, california 93940 
11. Department of Meteorology

Code 51

Naval Postgraduate School

Monterey, California 93940

12. Oceanographer of the Navy

The Madison Building

$732 \mathrm{~N}$. Washington street

Alexandria, Virginia 22314

13. Naval Oceanographic Office

Attn: Library

Washington, D. C. 20390

14. National Oceanographic Data Center I

Washington, D. C. 20390

15. Director, Maury Center for Ocean Sciences

Naval Research Laboratory

Washington, D. C. 20390

16. James E. Paquin

US NROTC Unit

Oregon State University

Corvallis, Oregon 
Sceurtu iassificatron of tilte, body of absturt and indexing annotation must be entered when the overall report is classified) 1 ORIGINATING ACTIVITY (Corporate ansthor)

Naval Postgraduate School

Monterey, California 93940 UNCLASSIFIED

A LABORATORY EXPERIMENT ON SURFACE WAVE

ATTENUATION DUE TO UNDERWATER TURBULENCE

4 DESCRIPTIVE NOTES (Type of report and,inclusive dates)

Thesis

5. AUTHOR(S) (First name, middle initial, last name)

James Edward Paquin, Lieutenant, United States Navy

\begin{tabular}{|c|c|c|}
\hline $\begin{array}{l}\text { REPORT DATE } \\
\text { December } 1968\end{array}$ & $\begin{array}{c}\text { 7a. TOTAL NO OFPAGES } \\
61\end{array}$ & $\begin{array}{r}\text { 7b. NO. OF REFS } \\
2\end{array}$ \\
\hline $\begin{array}{l}\text { 8a. CONTRACT OR GRANT NO. } \\
\text { b. PROJECY NO }\end{array}$ & 9a. ORIGINATOR'S REPORT & $E R(S)$ \\
\hline 9 & $\begin{array}{l}\text { 9b. OTHER REPORT NO(S) } \\
\text { this report) }\end{array}$ & her numbers that may be as signed \\
\hline
\end{tabular}

Distribution of this document is unlimited.

11. SUPPLEMENTARY NOTES

Naval Postgraduate School

Monterey, California

The attenuation of surface waves caused by underwater turbulence was investigated in a wave-tank experiment. The waves studied (frequencies ranging from 1.2 to 12.3 Hertz) were strongly attenuated by a zone of grid-generated turbulence. This attenuation depended on the length of the turbulent region, and on the frequency of the incident wave. The equation governing attenuation was:

$$
h=h_{0} e^{-a x}
$$

where $h$ is wave height, $h$ is undisturbed wave height, $x$ is the length of the turbulent region, and $a$ is an attenuation coefficient proportional to the cube root of frequency. It was also noted that the waves were shifted in phase as they passed through the turbulence, and that the magnitude of this shift increased with frequency. The quantitative results of the experiment were obtained from measurements of nearly sirusoidal waves. They were confirmed, qualitatively, for a continuous spectrum of waves by measurement of wind-generated model sea surface. 


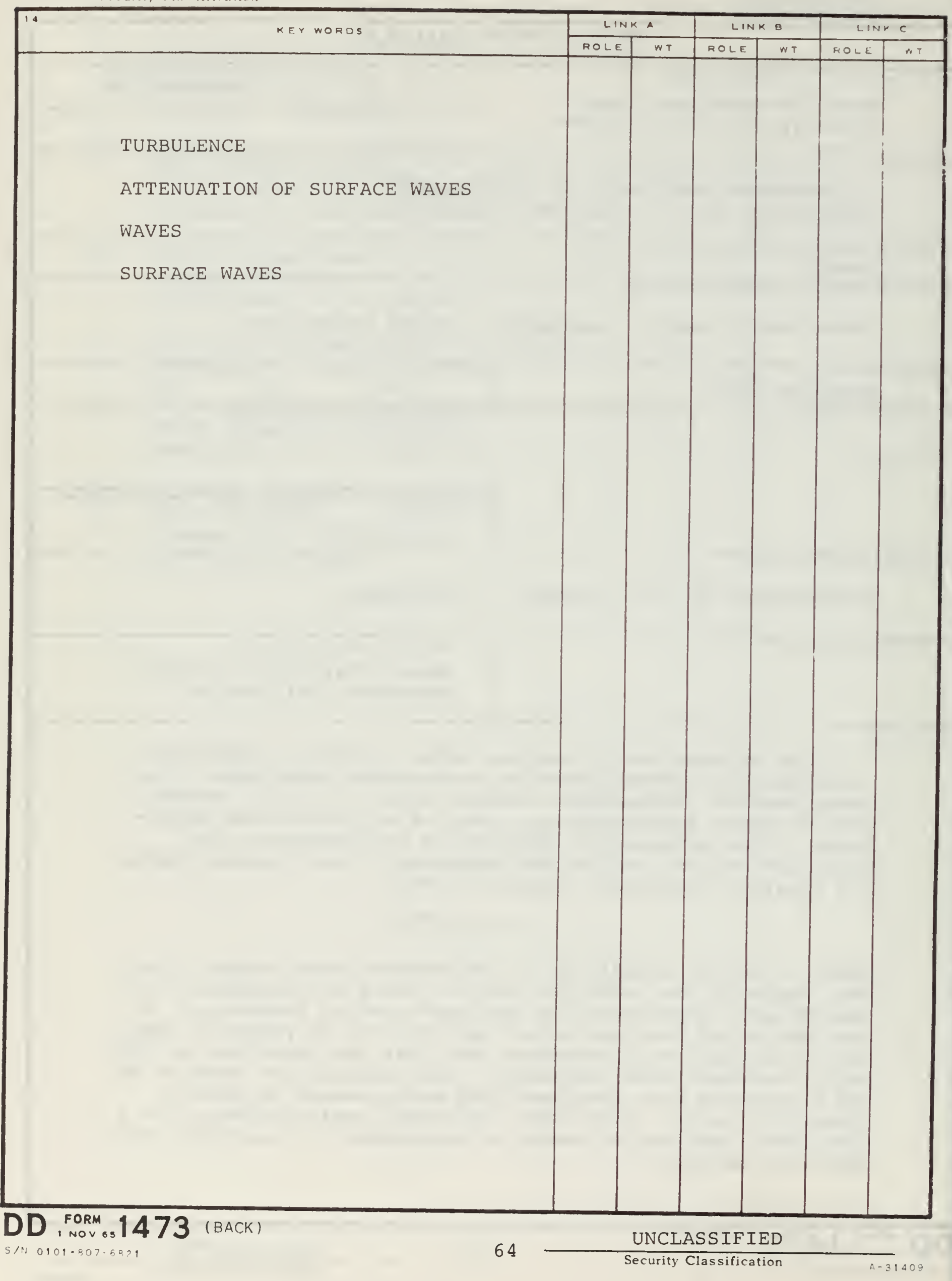








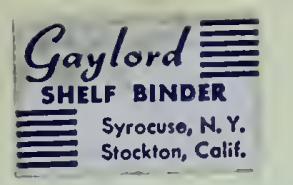



experiment on surface wave

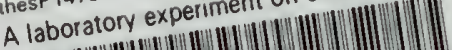

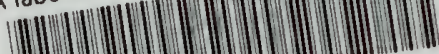

- III IIIIII 971732

32768001971732

DUDLEY. KNOX 